\title{
Formononetin, an isoflavone, activates AMP-activated protein kinase/ $\beta$-catenin signalling to inhibit adipogenesis and rescues C57BL/6 mice from high-fat diet-induced obesity and bone loss
}

\author{
Jyoti Gautam ${ }^{1}$, Vikram Khedgikar ${ }^{1}$, Priyanka Kushwaha ${ }^{1}$, Dharmendra Choudhary ${ }^{1}$, Geet Kumar Nagar ${ }^{1}$, \\ Kapil $\mathrm{Dev}^{2}$, Preety Dixit ${ }^{2}$, Divya Singh ${ }^{2}$, Rakesh Maurya ${ }^{2}$ and Ritu Trivedi ${ }^{1}{ }^{*}$ \\ ${ }^{1}$ Endocrinology Division, CSIR-Central Drug Research Institute, Lucknow 226031, India \\ ${ }^{2}$ Medicinal and Process Chemistry Division, CSIR-Central Drug Research Institute, Lucknow 226031, India
}

(Submitted 20 August 2016 - Final revision received 21 December 2016 - Accepted 9 January 2017)

\section{Abstract}

Balance between adipocyte and osteoblast differentiation is the key link of disease progression in obesity and osteoporosis. We have previously reported that formononetin (FNT), an isoflavone extracted from Butea monosperma, stimulates osteoblast formation and protects against postmenopausal bone loss. The inverse relationship between osteoblasts and adipocytes prompted us to analyse the effect of FNT on adipogenesis and in vivo bone loss, triggered by high-fat diet (HFD)-induced obesity. The anti-obesity effect and mechanism of action of FNT was determined in 3T3-L1 cells and HFD-induced obese male mice. Our findings show that FNT suppresses the adipogenic differentiation of 3T3-L1 fibroblasts, through down-regulation of key adipogenic markers such as PPAR $\gamma$, CCAAT/enhancer-binding protein alpha (C/EBP $\alpha$ ) and sterol regulatory element-binding protein (SREBP) and inhibits intracellular TAG accumulation. Increased intracellular reactive oxygen species levels and AMP-activated protein kinase (AMPK) activation accompanied by stabilisation of $\beta$-catenin were attributed to the anti-adipogenic action of FNT. In vivo, 12 weeks of FNT treatment inhibited the development of obesity in mice by attenuating HFD-induced body weight gain and visceral fat accumulation. The anti-obesity effect of FNT results from increased energy expenditure. FNT also protects against HFD-induced dyslipidaemia and rescues deterioration of trabecular bone volume by increasing bone formation and decreasing bone resorbtion caused by HFD. FNT's rescuing action against obesity-induced osteoporosis commenced at the level of progenitors, as bone marrow progenitor cells, obtained from the HFD mice group supplemented with FNT, showed increased osteogenic and decreased adipogenic potentials. Our findings suggest that FNT inhibits adipogenesis through AMPK/ $\beta$-catenin signal transduction pathways and protects against HFD-induced obesity and bone loss.

\section{Keywords: Isoflavones: Obesity: Bone loss: AMP-activated protein kinase: TNF $\alpha$ : Micro-computed tomography}

Adipocytes play a critical role in energy balance. The connection between fuel utilisation and skeletal re-modelling begins in the bone marrow with lineage allocation of mesenchymal stem cells to adipocytes or osteoblasts ${ }^{(1)}$. Excessive consumption of high-fat diet (HFD) leads to obesity, and this results in deteriorated bone microarchitecture ${ }^{(2-4)}$. Ageing, secondary causes of osteoporosis including diabetes mellitus, glucocorticoids and immobility are also associated with bone marrow adiposity ${ }^{(5)}$. Importantly, fat in bone marrow might not only suppress osteoblasts but also might promote bone resorption, because marrow adipocytes secrete certain inflammatory cytokines capable of recruiting osteoclasts ${ }^{(6)}$. Therefore, understanding the signalling pathways that govern adipose differentiation may provide therapeutic strategies for both obesity and bone-related disorders.
There are various regulatory pathways that control both diseases. AMP-activated protein kinase (AMPK) plays a central role in the regulation of energy metabolism ${ }^{(7)}$. The ability of AMPK to switch cells from an anabolic to a catabolic state suggests that activators of the kinase might be effective agents for the treatment of obesity, type 2 diabetes and the metabolic syndrome. Recent studies have shown the association between AMPK and winglessrelated integration site (Wnt) $/ \beta$-catenin signalling ${ }^{(8,9)}$. The $\mathrm{Wnt} / \beta$ catenin pathway has been shown to inhibit adipogenesis by maintaining pre-adipocytes in an undifferentiated state through inhibition of CCAAT/enhancer-binding protein alpha $(C / E B P \alpha)$ and $P P A R \gamma^{(10,11)}$ as well as to increase osteogenesis by directly regulating the runt-related transcription factor 2 (Runx2) gene ${ }^{(12)}$. Wingless-related integration site-10b (Wnt-10b) has been found to be a potent inhibitor of adipogenesis ${ }^{(13,14)}$. Forced expression of

Abbreviations: AMPK, AMP-activated protein kinase; BAT, brown adipose tissue; BMSC, bone marrow stromal cell; C/EBP, CCAAT/enhancer-binding protein; DMEM, Dulbecco's modified Eagle medium; FBS, fetal bovine serum.FNT, formononetin; GSK-3, glycogen synthase kinase-3; HFD, high-fat diet; OCN, osteocalcin; ROS, reactive oxygen species; RUNX2, runt-related transcription factor 2; SREBP, sterol regulatory element-binding protein; UCP1, uncoupling protein 1; Wnt-10b, wingless-related integration site-10b.

* Corresponding author: R. Trivedi, fax +91 522277 1941, email ritu_trivedi@cdri.res.in 
Wnt-10b or Wnt-1 in 3T3-L1 cells stabilises free cytosolic $\beta$-catenin by preventing proteasomal degradation of $\beta$-catenin and inhibiting the induction of PPAR $\gamma$, thereby blocking adipogenesis ${ }^{(15,16)}$. Moreover, the serine/threonine kinase glycogen synthase kinase-3 (GSK-3) has been recognised to coordinate with AMPK in phosphorylation $^{(17)}$. However, some studies also report that $\beta$-catenin might inhibit adipogenesis by directly repressing transcription from the promoters of adipocyte genes ${ }^{(18,19)}$.

Previous studies suggest that isoflavones may exert inhibitory effects on adipose tissue enlargement through assorted molecular pathways ${ }^{(20-22)}$. Soya isoflavones have also been shown to be useful in preventing and treating postmenopausal osteoporosis because of their similarity in structure to oestradiol (E2), as E2 is a major regulator of adipocyte development and number in females and males ${ }^{(23)}$. Formononetin (FNT) (7-hydroxy-3(4-methoxyphenyl) chromone or 4'-methoxy daidzein) is a soya isoflavonoid, found abundantly in traditional Chinese medicine Astragalus mongholicus (Bunge) and Trifolium pratense L. (red clover) and in an Indian medicinal plant Butea monosperma ${ }^{(24,25)}$. Studies have shown that FNT induces apoptosis through various signalling pathways in prostate, breast and cervical cancer cell lines ${ }^{(26-28)}$. Moreover, our previous studies have shown that FNT stimulates osteoblast differentiation via the activation of $\mathrm{p} 38$ mitogen-activated protein kinase $(M A P K)$ pathway, and oral administration of FNT in rodents increases bone mineral density at various anatomical positions ${ }^{(29,30)}$. However, the anti-obesity effect of FNT has not been explored. In this study, we show that FNT inhibits adipogenesis in 3T3-L1 pre-adipocytes and protects against obesity-induced bone loss in a HFD mouse model via AMPK and $\beta$-catenin activation. Overall, our study points to the fact that FNT acts as a dual therapeutic molecule both for obesity as well as obesity-induced bone loss.

\section{Methods}

\section{In vitro studies}

Cell culture and reagents. The 3T3-L1 fibroblast cell line was maintained in Dulbecco's Modified Eagle's medium (DMEM)/high glucose (Sigma-Aldrich) with 10\% newborn calf serum (Gibco ${ }^{\mathrm{TM}}$; Life Technologies), 100 units $/ \mathrm{ml}$ penicillin and $100 \mu \mathrm{g} / \mathrm{ml}$ streptomycin at $37^{\circ} \mathrm{C}$ in a $5 \% \mathrm{CO}_{2}$ incubator. To induce differentiation, $100 \%$ confluent 3T3-L1 pre-adipocytes (day 0) were stimulated for $2 \mathrm{~d}$ with MDI media (0.5 mm-3-isobutyl-1-methylxanthine (Sigma-Aldrich), $1 \mu \mathrm{M}$ dexamethasone (DEX) (Sigma-Aldrich) and $5 \mu \mathrm{g} / \mathrm{ml}$ insulin $\left(\mathrm{Gibco}^{\mathrm{TM}}\right)$ in $\mathrm{DMEM} / 10 \%$ fetal bovine serum (FBS; HyClone)). On day 3, the MDI media were replaced with differentiation media $(5 \mu \mathrm{g} / \mathrm{ml}$ insulin in DMEM/10\% FBS). On day 6 , the differentiation media were replaced with growth media (DMEM/10\% FBS). The cell culture media were changed every $2 \mathrm{~d}$ until full differentiation - that is, up to $9 \mathrm{~d}^{(28)}$. To investigate the effect of FNT on adipogenesis in 3T3-L1, cells were differentiated in the presence or absence of FNT up to $9 \mathrm{~d}$. Compound C (Sigma) was dissolved in dimethyl sulphoxide (DMSO) for cell culture studies $(20-\mathrm{mm} \text { stock })^{(31)}$. Cells were maintained in differentiation medium with compound $\mathrm{C}(10 \mu \mathrm{M})$, with or without FNT (10 nm), from day 0 to day 3 in six-well plates.

\section{3-(4,5-Dimethylthiazol-2-yl)-2,5-diphenyltetrazolium}

bromide assay. The effect of FNT on cell viability of 3T3-L1 pre-adipocytes and differentiated adipocytes was analysed using 3-(4,5-dimethylthiazol-2-yl)-2,5-diphenyltetrazolium bromide (MTT). The 3T3-L1 pre-adipocytes were seeded at a density of $3 \times 10^{3}$ cells/well in ninety-six-well plates. Both preadipocytes and mature adipocytes were incubated in culture medium, with or without FNT, for $48 \mathrm{~h}$. After $48 \mathrm{~h}$, the cells were incubated in the dark with an MTT solution for $4 \mathrm{~h}$ at $37^{\circ} \mathrm{C}$. Formazan crystal products were dissolved in DMSO. Absorbance was measured spectrophotometrically at $570 \mathrm{~nm}$ (Molecular Devices).

Oil Red O staining. Differentiated 3T3-L1 adipocytes were fixed with $4 \%$ formaldehyde for $20 \mathrm{~min}$. Cells were then incubated with the Oil Red O (ORO) solution for $20 \mathrm{~min}$ and washed with PBS. The stained lipid droplets and cell morphology were observed by light microscopy (Nikon). Stained oil droplets were dissolved with isopropanol and quantified by spectrophotometry at $490 \mathrm{~nm}$.

Measurement of intracellular reactive oxygen species generation. Differentiated 3T3-L1 cells were treated with or without FNT (10 nm concentration), lipopolysaccharide (LPS) $(100 \mathrm{ng} / \mathrm{ml})$ and $N$-acetyl-L-cysteine (NAC) $(10 \mu \mathrm{M})$ for $48 \mathrm{~h}^{(32)}$. Reactive oxygen species (ROS) determination was based on the oxidation of non-fluorescent 2,7-dichlorodihydrofluorescein diacetate (DCFDA) into a fluorescent dye - 2,7-dichlorofluorescein - by peroxide or nitric oxide production. Cells were washed with PBS and incubated for $30 \mathrm{~min}$ at $37^{\circ} \mathrm{C}$ in the dark with the oxidation-sensitive probe DCFDA $(10 \mu \mathrm{g} / \mathrm{ml})$ (Molecular Probes). Lysates were collected in $0 \cdot 1 \%$ Triton X-100, and production of ROS was measured by changes in fluorescence at an excitation wavelength of $495 \mathrm{~nm}$ and an emission wavelength of $525 \mathrm{~nm}$.

Real-time PCR. Cells were homogenised using TRIzol reagent (Invitrogen), and total RNA was extracted according to the manufacturer's protocol. For real-time PCR, complementary DNA was synthesised with Revert Aid cDNA synthesis kit (Fermentas) using $2 \cdot 0 \mu \mathrm{g}$ of total RNA. SYBR green chemistry was used for quantitatively determining the relative expressions of transcripts of all genes. All genes were analysed using the Light Cycler 480 (Roche Molecular Biochemicals) real-time PCR machine. Glyceraldehyde 3-phosphate dehydrogenase was used as an endogenous control in the comparative cycle-threshold $\left(C_{T}\right)$ method. Primers for each specific gene are shown in the online Supplementary Table S2.

Western blot analysis. Cell pellets and tissues were lysed in radioimmunoprecipitation assay lysis buffer with $1 \%$ phenylmethylsulfonyl fluoride, $1 \%$ protease inhibitor cocktail and $1 \%$ sodium orthovanadate. After treatment on ice for $30 \mathrm{~min}$, cell lysates were clarified by centrifugation at $11419 \mathrm{~g}$ for $30 \mathrm{~min}$ at $4{ }^{\circ} \mathrm{C}$ to remove cell debris, and the protein content was measured by the Bradford method. Aliquots of the lysates were subjected to $10 \%$ SDS-PAGE (with 5\% stacking gel) 
and transferred to a polyvinylidene fluoride membrane. The membranes were probed with $\operatorname{PPAR} \gamma, \mathrm{C} / \mathrm{EBP} \alpha, \beta$-catenin, GSK-3 $\beta$, phospho-GSK-3 $\beta$ (Ser-9) AMPK, phospho-AMPK $\alpha$ (T172) and $\beta$-actin antibodies (Abcam) followed by incubation with horseradish peroxidase-conjugated secondary antibodies (Cell Signaling Technology). $\beta$-Actin was used as a reference to normalise differences in the amounts of protein between samples. Membranes were developed using an enhanced chemiluminescence kit (Millipore) with ImageQuant LAS 4000 (GE Healthcare).

Immunofluorescence assay. After culturing 3T3-L1 cells in differentiation medium, with or without FNT, for $3 \mathrm{~d}$, the cells were fixed with $80 \%$ ethanol for $10 \mathrm{~min}$, incubated in PBS containing $0.5 \%$ Triton X-100 and washed three times with PBS. Cells were incubated with mouse monoclonal antibody against $\beta$-catenin (1:50) for $2 \mathrm{~h}$ at room temperature, followed by incubation with anti-mouse IgG Alexa 488 antibody (1:50) for $1 \mathrm{~h}$. After washing with PBS, the cells were incubated for $1 \mathrm{~min}$ with DAPI $(0.1 \mu \mathrm{g} / \mathrm{ml})$ for nuclear staining at room temperature. Finally, the cells were examined and photographed using a fluorescent microscope (Eclipse 80i; Nikon) with the aid of an appropriate filter (excitation at $495 \mathrm{~nm}$ and emission at $519 \mathrm{~nm}$ ).

\section{In vivo studies}

Animals and diet. All animal care and experimental procedures were approved by the Institutional Animal Ethics Committee (IAEC) with the number IAEC/2013/16, which followed the guidelines of the Committee for the Purpose of Control and Supervision of Experiments on Animals and conformed to the international norms of the Indian National Science Academy. In total, fifty, 4-week-old, male C57BL/6 mice were obtained from the National Laboratory Animal Centre and were randomly assigned to five groups: chow, HFD and HFD + FNT (0.1, 1, $10 \mathrm{mg} / \mathrm{kg}$ per d) of ten mice each. Animals were kept in a $12 \mathrm{~h}$ light $-12 \mathrm{~h}$ dark cycle, with controlled temperature $\left(22-24^{\circ} \mathrm{C}\right)$ and humidity (50-60\%), and were given ad libitum access to water and food. The control group was fed standard chow diet, and the remaining groups were fed HFD (D12109, $40 \% \mathrm{kcal} \%$ fat; Research Diets, Inc.) (online Supplementary Table S1) for 12 weeks. Body weight was recorded weekly.

Biochemical analysis. Total cholesterol (TC), TAG, HDL and LDL were determined by colorimetric assays using a semiautomatic biochemistry analyser. TNF $\alpha$ and osteocalcin $(\mathrm{OCN})$ levels were assayed using ELISA kits (Immunodiagnostic Systems Ltd) following the manufacturer's protocols ${ }^{(4)}$.

Bone marrow cell culture. At the end of 12 weeks, bone marrow cells (BMC) were isolated from all mice groups and cultured according to our previously published protocol $^{(4,22,33)}$. For osteogenic differentiation, released bone marrow cells were collected and plated in forty-eight-well and twelve-well plates $\left(1 \times 10^{5}, 2 \times 10^{6}\right.$ cells/well $)$ in the culture medium, consisting of $\alpha$-minimum essential media ( $\alpha$-MEM), supplemented with $10 \%$ FBS, $100 \mathrm{~nm}$ DEX, $10 \mathrm{~mm} \beta$-glycerophosphate and $50 \mu \mathrm{g} / \mathrm{ml}$ ascorbic acid, for alkaline phosphatase (ALP) activity and mineralisation, respectively. Both the ALP activity and the extracted stain (mineralised $\mathrm{Ca}$ nodules stained with alizarin) were quantified by an ELISA plate reader at $405 \mathrm{~nm}$.

For adipogenic differentiation, $1 \times 10^{7}$ BMCs were seeded in twenty-four-well plates and cultured in an adipogenic medium (DMEM) containing 1.0 $\mathrm{M}$ DEX, 0.5 mM-isobutylmethylxanthine, $100 \mu \mathrm{m}$-indomethacin, $10 \% \mathrm{FBS}$ and insulin $(10 \mu \mathrm{g} / \mathrm{ml})$ for $7 \mathrm{~d}$. On day 3 , the medium was replaced with complete growth medium containing only insulin $(10 \mu \mathrm{g} / \mathrm{ml})$. The medium was replaced every $3 \mathrm{rd}$ day, and this was continued for $21 \mathrm{~d}$. To quantify the incorporation of lipid, the area stained with ORO was measured by taking photomicrographs, and the extracted stain was quantified using an ELISA plate reader at $490 \mathrm{~nm}^{(4)}$.

Real-time PCR. Bone and adipose tissues were homogenised in liquid $\mathrm{N}_{2}$. Further procedures were carried out as described in the 'Real-time PCR' section of in vitro methods. Primers were designed using the Universal Probe Library (Roche Applied Sciences), and the sequences of primer sets for specific genes are shown in the online Supplementary Table $S 2^{(4,34)}$.

Ex vivo micro-computed tomography. Micro-computed tomography $(\mu \mathrm{CT})$ of excised bones was carried out using the SkyScan $1076 \mu$ CT scanner (Bruker MicroCT) as described earlier ${ }^{(4,33,35)}$. The X-ray source was set at $50 \mathrm{kV}$ and $200 \mathrm{~mA}$, with a pixel size of $9 \mu \mathrm{m}$. The bone samples were scanned at a voxel size of $9 \times 9 \times 9 \mu \mathrm{m}$. Reconstruction was carried out using SkyScan Nrecon software. A hundred projections were acquired over an angular range of $180^{\circ}$. Femora and tibia (cancellous bone) were analysed using CT analyser (CTAn, Skyscan) software. The threshold for analysis was determined empirically and set at 255 (scale 0-1000). For femoral and tibial metaphysis, 100 slices of secondary spongiosa were evaluated. $\mu \mathrm{CT}$ parameters bone volume/tissue volume (BV/TV), trabecular number (Tb.N), trabecular separation (Tb.Sp), trabecular thickness (Tb.Th), trabecular pattern factor (Tb.Pf) and the structure model index (SMI) of the distal femoral metaphysis (covering secondary spongiosa and the secondary ossification centre) and the proximal tibial metaphysis were evaluated. CTvol software was used to create three-dimensional (3D) models of bones ${ }^{(4,36)}$.

Bone histomorphometry. Cross-sections (50-mm thickness) of the terminal periosteal regions of undecalcified femoral diaphysis of each mouse were obtained using an Isomet-Slow Speed Bone Cutter (Buehler). Images were captured using Leica-Qwin software (Leica Microsystems Inc.), and bone forming rate/bone surface (BFR/BS) and mineral appositional rate (MAR) were calculated ${ }^{(34)}$.

Bone mechanical strength. Femora were subjected to a threepoint bending test with bone strength tester model TK-252C (Muromachi Kikai Co. Ltd) for assaying bone mechanical strength according to previously published protocols ${ }^{(34)}$.

Histology of adipose tissue. Abdominal fat pads were collected and fixed in PBS containing $4 \%$ formalin, were embedded in paraffin and $6-\mu$ m-thick sections were stained with 
(A)<smiles>COc1ccc(-c2coc3cc(O)ccc3c2=O)cc1</smiles>

Formononetin
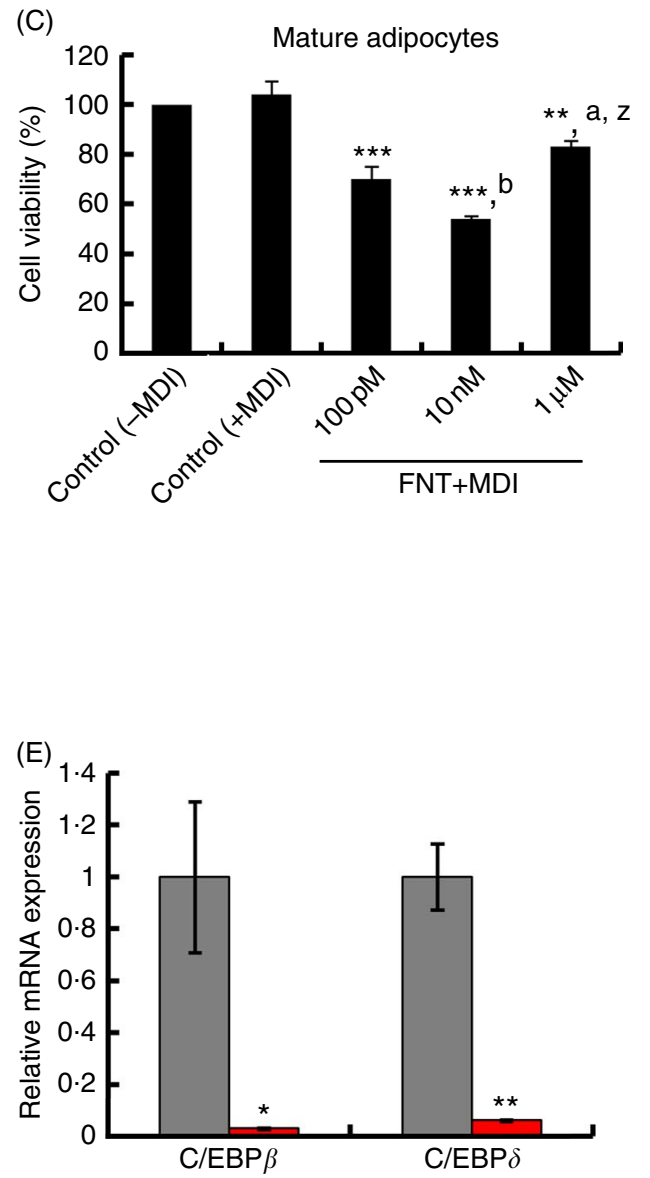

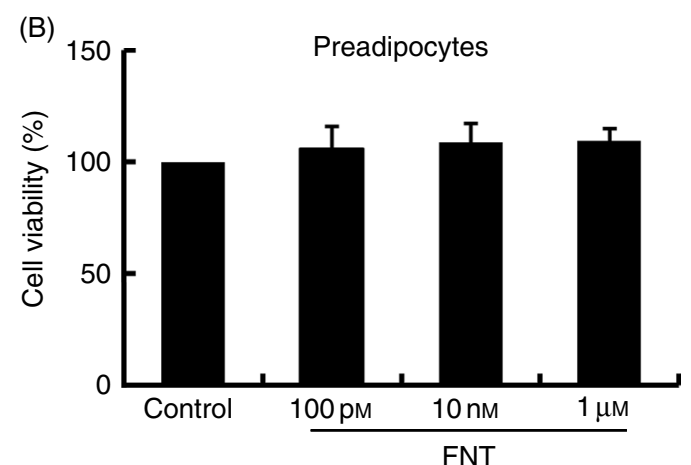

(D)
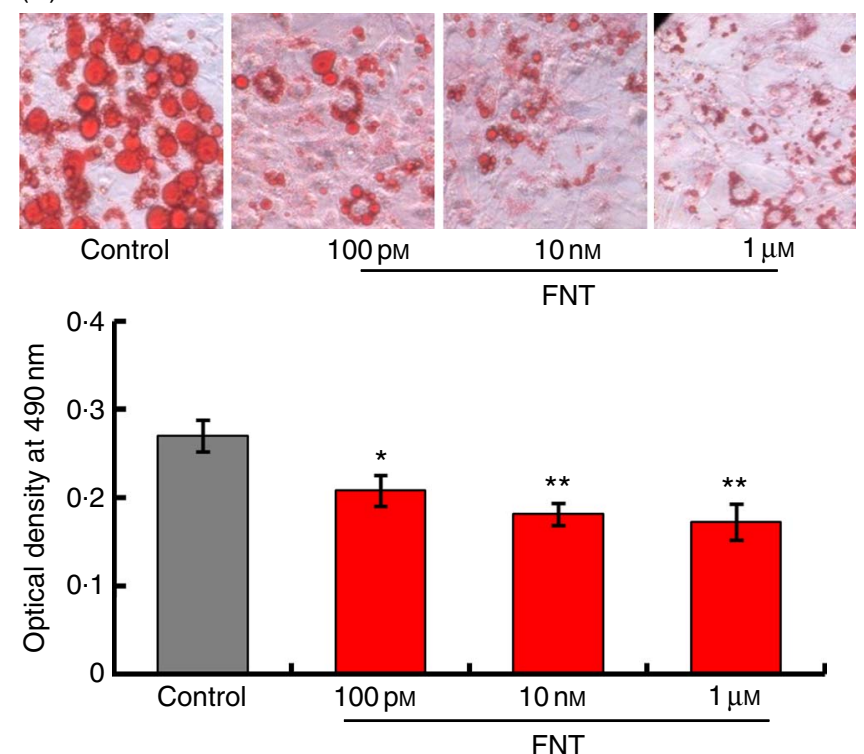

(F)

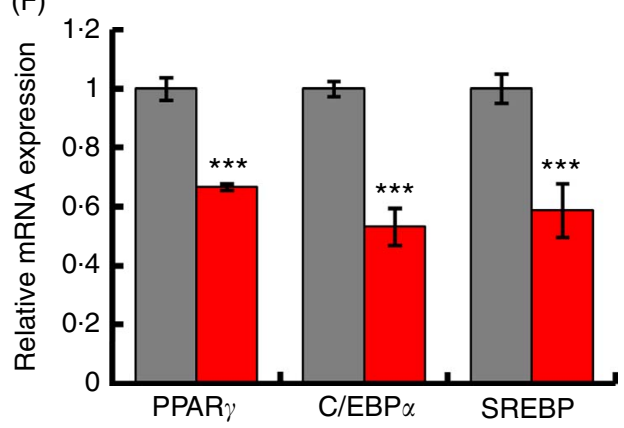

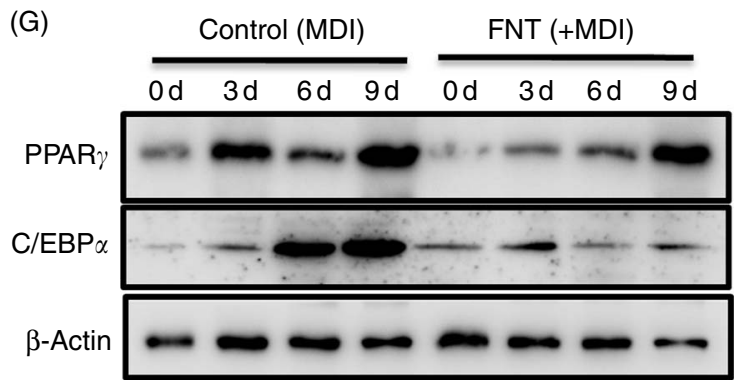

Fig. 1. (For caption see following page) 
haematoxylin-eosin (H\&E). Average adipocyte size of the fat pad was quantified by capturing four independent fields per blinded slide using ImageJ software (National Institutes of Health) and expressed in $\mu \mathrm{m}^{2} /$ adipocyte $^{(37)}$.

\section{Statistical analysis}

Values are expressed as means with their standard errors. Comparisons of each parameter among multiple treatments or groups were analysed by one-way ANOVA followed by Neuman-Keuls post hoc tests using Prism version 3.0 software. Student's $t$ test was used to study the statistical significance in experiments with only two treatments. Probability values $<0.05$ were considered to be statistically significant.

\section{Results}

Formononetin inhibits adipogenesis of 3T3-L1 pre-adipocytes

The chemical structure of the isoflavone FNT is shown in Fig. 1(A). To examine whether FNT possesses an inhibitory effect on cell viability, we tested the effect of FNT on both preadipocytes and mature adipocytes. Both pre-adipocytes and mature adipocytes were treated with different concentrations (100 pm, $10 \mathrm{~nm}, 1 \mu \mathrm{m}$ ) of FNT for $48 \mathrm{~h}$. After treatment, the number of live cells was determined by MTT assay. Results show that $48 \mathrm{~h}$ of FNT treatment did not affect the viability of 3T3-L1 pre-adipocytes (Fig. 1(B)); however, FNT significantly decreased the cell viability of mature adipocytes at concentrations of $1 \mu \mathrm{m}$, $10 \mathrm{~nm}$ and $100 \mathrm{~nm}$. The maximum cell viability decrease was found at $10 \mathrm{~nm}$ concentration, approximately $48 \%$ (Fig. 1(C)), of FNT. To examine the effect of FNT on adipogenesis, 3T3-L1 cells were differentiated in the presence or absence of FNT from day 0 to 9. FNT treatment significantly inhibited lipid accumulation in mature 3T3-L1 adipocytes at concentrations of $100 \mathrm{pm}, 10 \mathrm{~nm}$ and $1 \mu \mathrm{M}$, as shown in Fig. 1(D). Accumulation of ORO-stained lipid droplets was visible in most of the untreated control 3T3-L1 adipocytes (Fig. 1(D), upper panel); however, the number of detectable stained droplets decreased in the presence of FNT. Compared with the control, FNT decreased the percentage of adipogenesis by $36 \cdot 2,32 \cdot 7$ and $30.5 \%$ at concentrations of $100 \mathrm{pm}, 10 \mathrm{~nm}$ and $1 \mu \mathrm{m}$, respectively, as shown in the graph (Fig. 1(D), lower panel). As we found that FNT decreases cell viability in mature adipocytes, we examined whether the inhibitory effect of FNT could be related to apoptosis. We found that FNT has the ability to impede the process of adipogenesis by blocking the G1/S phase of the cell cycle; however, only a small population of cells (approximately $0.7 \%$ ) undergoes apoptosis after treatment with FNT (online Supplementary Fig. S1A).
It is possible that decreased cell viability by FNT treatment may account for mitigation of cell proliferation rather than an apoptotic effect. For further experiments, $10 \mathrm{~nm}$ of FNT was used. Next, we investigated the expressions of $C / E B P \beta$ and $C / E B P \delta$. The expressions of both genes increased during early stages of differentiation. FNT treatment for $48 \mathrm{~h}$ significantly reduced the expressions of $C / E B P \beta(P<0.05)$ and $C / E B P \delta(P<0.01)$ in differentiation-induced 3T3-L1 cells compared with control cells (Fig. 1(E)). Next, we differentiated 3T3-L1 cells with or without FNT for $9 \mathrm{~d}$. The expressions of major adipogenic transcription markers $P P A R \gamma, C / E B P \alpha$ and sterol regulatory element-binding protein $(S R E B P)$ were examined. We found that FNT treatment significantly reduced the expressions of all major transcription factors $(P<0.001)$ (Fig. 1(F)), compared with non-treated cells. These data were also corroborated at the protein level (Fig. 1(G); online Supplementary Fig. S1C).

Formononetin induces reactive oxygen species generation and activates AMP-activated protein kinase/ $\beta$-catenin signalling

We next investigated the mechanism behind the antiadipogenic action of FNT. Several reports suggest an involvement of ROS in the signal transduction pathways leading to inhibition of lipid accumulation ${ }^{(21,38)}$. FNT treatment for $48 \mathrm{~h}$ significantly increased ROS generation $(P<0 \cdot 001)$, which was comparable with ROS induced by LPS, a positive control. Treatment with 10-mm NAC (a thiol-containing antioxidant) reduced ROS generation, whereas treatment with NAC and with FNT (10 nM) again increased ROS generation.

To examine whether AMPK is activated because of ROS generation induced by FNT, 3T3-L1 cells were treated with or without FNT up to $9 \mathrm{~d}$, and AMPK activation was examined. Fig. 2(b) shows that the addition of FNT increased phosphorylation of AMPK day dependently, without affecting the protein level of AMPK, suggesting a direct regulatory role of FNT on AMPK activation in adipocytes. Along with AMPK activation, we also investigated whether the FNT-induced anti-adipogenic effect is $\beta$-catenin dependent. We found increased $\beta$-catenin levels in cells treated with FNT compared with controls (Fig. 2(b) and (c)). Nonetheless, there was an increase in phospho-GSK-3 $\beta$ (Ser-9) levels (Fig. 2(b) and (c)). Inhibition of a serine/threonine kinase, GSK- $3 \beta$, is a critical event in $\beta$-catenin stabilisation and nuclear translocation. To confirm the stabilisation of $\beta$-catenin, we investigated the effect on upstream markers at transcriptional levels. mRNA expressions of Dickkopf-related protein-2 (DKK2), LDL receptor-related protein 5 (LRP5), Wnt-10b as well as $\beta$-catenin were examined. We found a significant decrease in the expression of $D K K 2 \quad(P<0.01), 2.5$-fold increase in the expression of LRP5, 2-fold increase in the expression of Wnt-10b

Fig. 1. (For figure see previous page) Effects of formononetin (FNT) on cell viability, lipid accumulation and adipogenic markers in 3 T3-L1 pre-adipocytes. (A) Chemical structure of FNT. (B) 3T3-L1 pre-adipocytes were treated with indicated concentrations of FNT for 48 h. 3-(4,5-Dimethylthiazol-2-yl)-2,5-diphenyltetrazolium bromide (MTT) reagent was added to the medium. The absorbance was read at $570 \mathrm{~nm}$. (C) Mature 3T3-L1 adipocytes were treated with or without FNT for $48 \mathrm{~h}$, and MTT absorbance was read at $570 \mathrm{~nm}$. (D) The morphological changes associated with cell differentiation were photographed after Oil Red $O$ staining (upper panel), and stained lipids were extracted and quantified by measuring absorbance at $490 \mathrm{~nm}$ (lower panel). mRNA expressions of adipogenic markers (E) CCAAT/enhancer-binding protein beta (C/EBP $\beta$ ) and C/EBP $\delta$ and (F) PPAR, C/EBPa and sterol regulatory element-binding protein (SREBP). (G) Day-dependent expressions of PPAR $y$ and C/EBPa were assessed by Western blotting. Results were obtained from three independent experiments in triplicate and are expressed as mean values with their standard errors, ${ }^{\star} P<0.05$, ${ }^{\star \star} P<0.01$, ${ }^{\star \star *} P<0.001$ v. control; ${ }^{a} P<0.05,100$ pм v. $1 \mu \mathrm{m}$; ${ }^{\mathrm{b}} P<0.01,100 \mathrm{pm}$ v. $10 \mathrm{~nm} ;{ }^{\mathrm{z}} P<0.001,10 \mathrm{~nm}$ v. $1 \mu \mathrm{m}$. E, F: $\square$, control; $\square$, FNT (10 nм). 
(a)

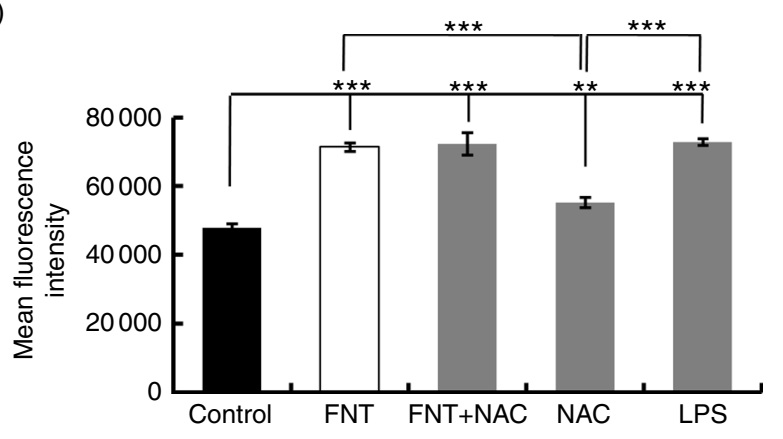

(b)
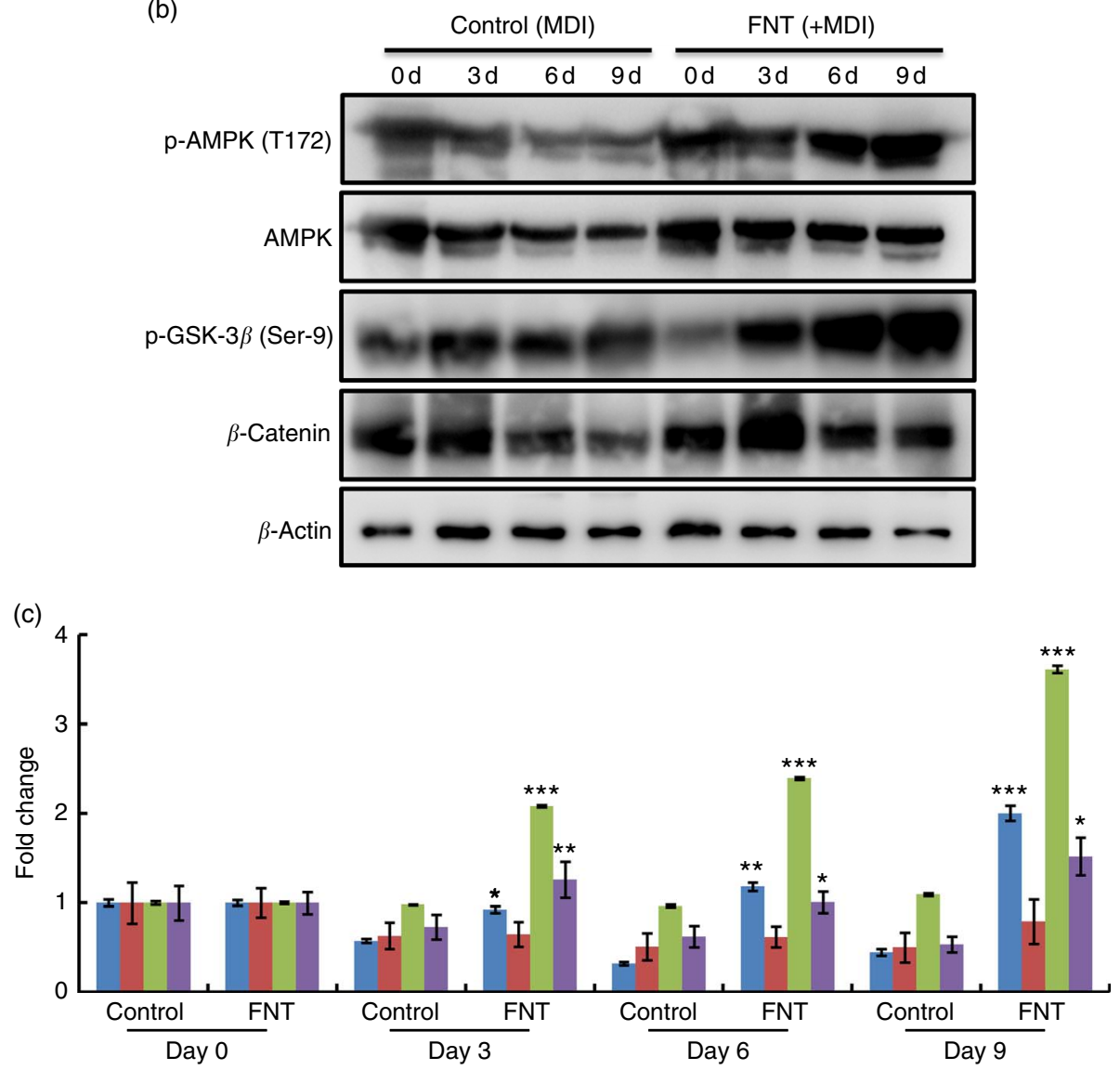

Fig. 2. Effect of FNT on reactive oxygen species (ROS) generation and AMP-activated protein kinase (AMPK) activation. Differentiated 3T3-L1 cells were treated with 10-nm formononetin (FNT), N-acetyl-L-cysteine (NAC) and lipopolysaccharide (LPS) for $48 \mathrm{~h}$. (a) ROS generation induced by FNT. 3T3-L1 cells were treated with or without 10-nM FNT up to 9 d. (b) Day-dependent expressions of phospho-AMPK (p-AMPK) (T172), AMPK, phospho-glycogen synthase kinase-3 $\beta$ (p-GSK-3 $\beta$ ) (Ser-9) and $\beta$-catenin by Western blotting. (c) Densitometric analyses of Western blot, showing fold change. Fold increase was calculated relative to control vehicletreated cells. Results were obtained from three independent experiments in triplicate and are expressed as mean values with their standard errors. ${ }^{*} P<0.05$, ${ }^{\star \star} P<0.01,{ }^{\star \star \star} P<0.001$ v. the corresponding controls. $\square, \mathrm{p}$-AMPK; $\square$, AMPK; $\square, \mathrm{p}$-GSK- $3 \beta ; \square, \beta$-catenin.

and 5-fold increase in the expression of $\beta$-catenin (Fig. 3(a)). Immunofluorescence staining also revealed the increased nuclear localisation of $\beta$-catenin with FNT treatment, as shown in Fig. 3(b).

Next, to confirm whether the activation of AMPK was associated with $\beta$-catenin, we inhibited the expression of AMPK with compound C (6-[4-[2-(1-Piperidinyl) ethoxy] phenyl]3-(4-pyridinyl) pyrazolo [1, 5-a] pyrimidine), a specific inhibitor of AMPK, and simultaneously checked the expression of $\beta$-catenin. There was a significant decrease in phosphorylated AMPK levels with decreased levels of $\beta$-catenin along with phosphorylated levels of Ser-9 GSK-3 $\beta$ residue (Fig. 3(c) and (d)). However, FNT treatment along with compound $\mathrm{C}$ restored their expressions (Fig. 3(c) and (d)).

\section{Formononetin exerts in vivo anti-obesity effect}

We next investigated in vivo the anti-obesity action of FNT in an HFD-induced obese mouse model. After 12 weeks, mice fed HFD showed higher body weights and more abdominal fat mass compared with mice fed a chow diet. Quantitative analysis 
(a)

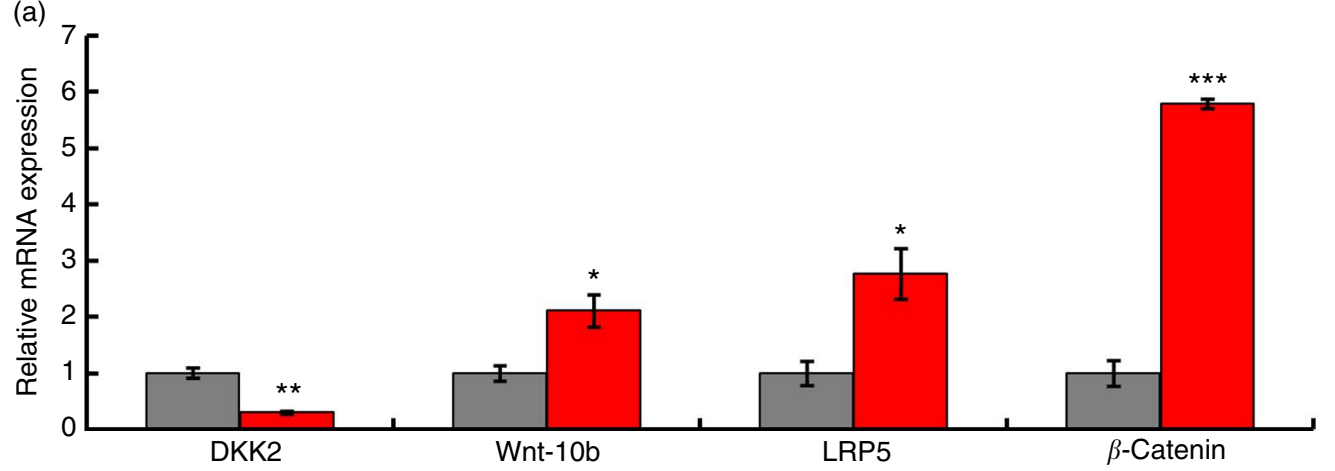

(b)
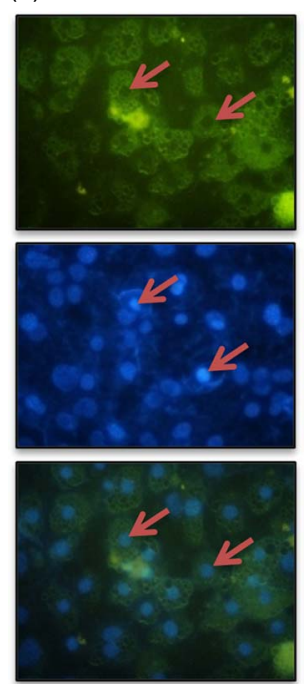

Control (MDI)
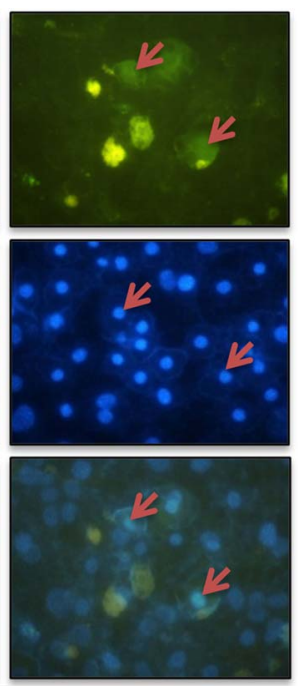

FNT (+MDI)

(c)

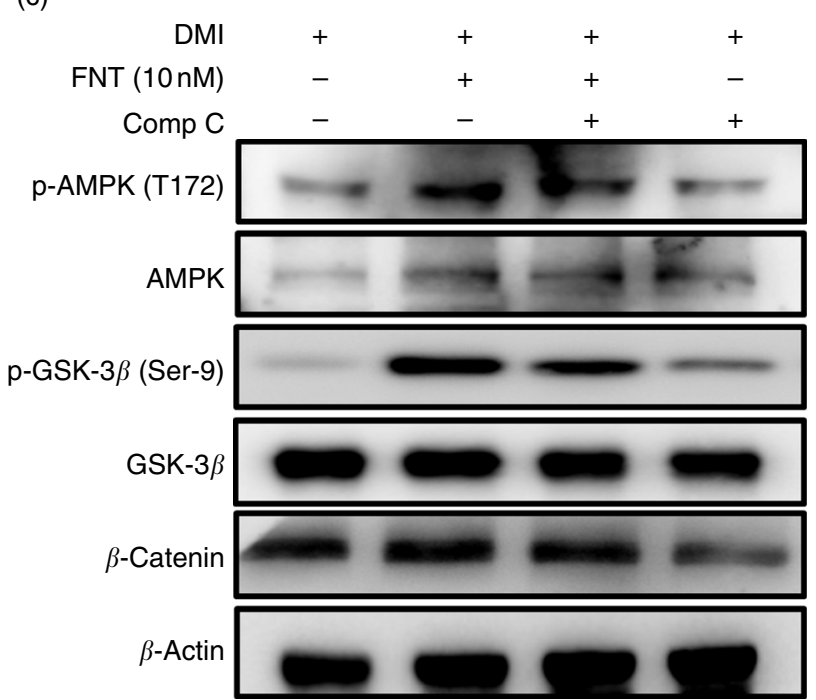

(d)

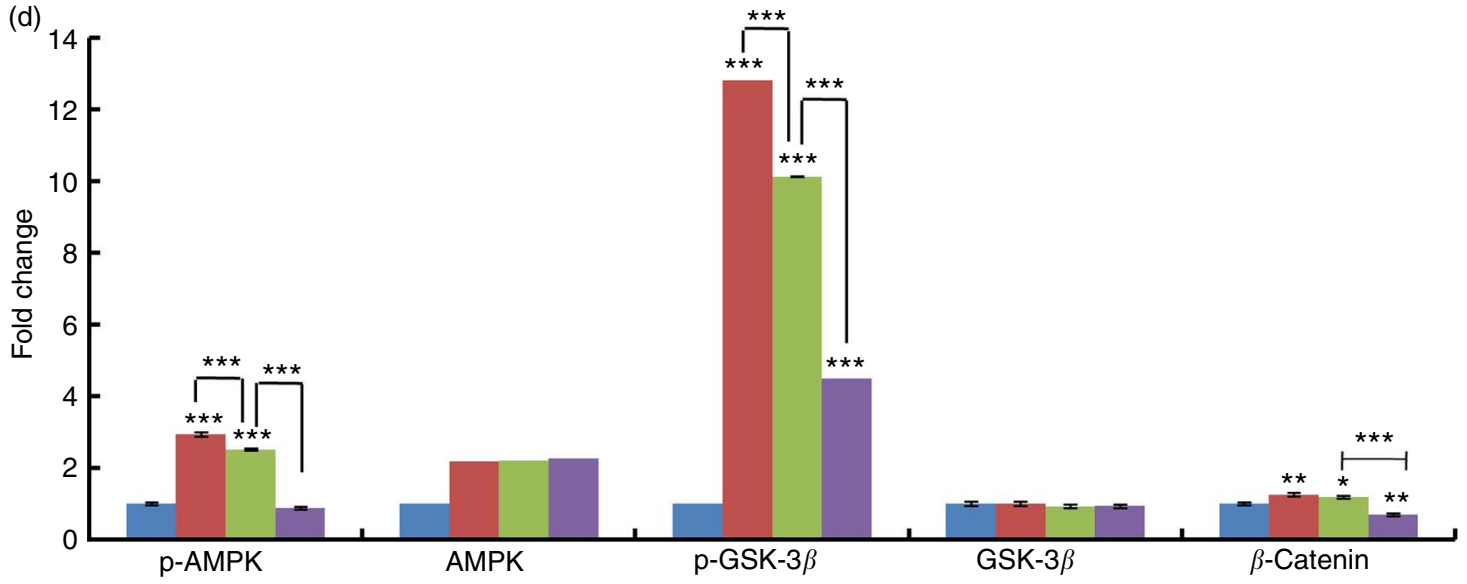

Fig. 3. Effect of formononetin (FNT) on wingless-related integration site (Wnt)/ $\beta$-catenin signalling activators. Post-confluent $3 T 3$-L1 pre-adipocytes were induced to differentiate in the absence or presence of FNT (added on day 0 of differentiation) for $9 \mathrm{~d}$. (a) mRNA expressions of Wnt signaling-related molecules, Dickkopf-related protein-2 (DKK2), LDL receptor-related protein 5 (LRP5), wingless-related integration site-10b (Wnt-10b), $\beta$-catenin. (b) Nuclear localisation of $\beta$-catenin in the presence or absence of FNT. 3T3-L1 cells were treated with or without 10-nM FNT or compound C (Comp C) for $48 \mathrm{~h}$. (c) Confirmation of AMP-activated protein kinase (AMPK) activation in the

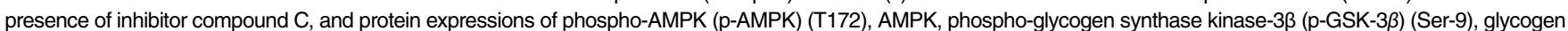

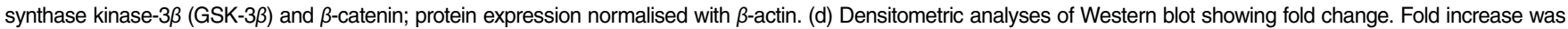
calculated relative to control vehicle-treated cells. Results were obtained from three independent experiments in triplicate and are expressed as mean values with their standard errors. ${ }^{\star} P<0.05,{ }^{\star \star} P<0.01,{ }^{\star \star \star} ~ P<0.001$ v. the corresponding controls. a: $\square$, Control; $\square$, FNT; d: $\square$, control; $\square$, FNT (MDI); $\square$, FNT (+MDI) + Comp C; $\square$, MDI + Comp C.

of total body weight gain indicated a significant reduction in obesity in the HFD group supplemented with FNT compared with the HFD group. The average final weights of mice were reduced by approximately $18 \%$ in the groups treated with $0 \cdot 1$, 1.0 and $10.0 \mathrm{mg} / \mathrm{kg}$ per d FNT (online Supplementary Fig. S3A). We did not observe any significant differences in food intake 
Table 1. Plasma biochemical parameters and food intake (Mean values with their standard errors; $n 10$ mice per group)

\begin{tabular}{|c|c|c|c|c|c|c|c|c|c|c|}
\hline & & & & & & & \multicolumn{4}{|c|}{ HFD + FNT } \\
\hline & \multicolumn{2}{|c|}{ Chow } & \multicolumn{2}{|c|}{ HFD } & \multicolumn{2}{|c|}{$\mathrm{HFD}+0.1 \mathrm{mg}$} & \multicolumn{2}{|c|}{$\mathrm{HFD}+1 \mathrm{mg}$} & \multicolumn{2}{|c|}{$\mathrm{HFD}+10 \mathrm{mg}$} \\
\hline & Mean & SEM & Mean & SEM & Mean & SEM & Mean & SEM & Mean & SEM \\
\hline \multicolumn{11}{|l|}{ Lipid parameters } \\
\hline $\mathrm{TC}(\mathrm{mmol} / \mathrm{l})$ & $1.78^{\star \star \star}$ & 0.35 & 3.49 & 0.20 & 3.38 & 0.18 & $2 \cdot 45^{\star}$ & 0.17 & $2 \cdot 03^{\star \star, b}$ & 0.24 \\
\hline TAG (mmol/l) & $0.46^{\star \star *}$ & 0.01 & 0.69 & 0.06 & $0.40^{\star \star \star}$ & 0.22 & $0.34^{\star \star *}$ & 0.04 & $0.40^{\star * \star}$ & 0.03 \\
\hline $\mathrm{LDL}(\mathrm{mmol} / \mathrm{l})$ & $0.27^{\star \star \star}$ & 0.01 & 0.54 & 0.06 & 0.40 & 0.03 & $0.30^{\star \star \star}$ & 0.03 & $0.26^{\star \star \star}$ & 0.03 \\
\hline $\mathrm{HDL}(\mathrm{mmol} / \mathrm{l})$ & $0.72^{\star \star \star}$ & 0.04 & 0.46 & 0.04 & 0.45 & 0.03 & $0.66^{\star}$ & 0.06 & $0.76^{\star \star}$ & 0.08 \\
\hline VLDL (mmol/l) & $0.21^{\star \star \star}$ & 0.01 & 0.32 & 0.03 & $0 \cdot 18^{\star \star \star}$ & 0.01 & $0.15^{\star \star \star}$ & 0.01 & $0 \cdot 18^{\star \star \star}$ & 0.01 \\
\hline \multicolumn{11}{|l|}{ Biochemical markers } \\
\hline TNFa $(\mathrm{pg} / \mathrm{ml})$ & $58 \cdot 40^{\star \star \star}$ & $2 \cdot 76$ & $149 \cdot 61$ & $7 \cdot 81$ & $68 \cdot 30^{\star \star \star}$ & 3.27 & $91 \cdot 75^{\star \star}$ & $12 \cdot 26$ & $97 \cdot 16^{\star \star}$ & $11 \cdot 81$ \\
\hline $\mathrm{OCN}(\mathrm{ng} / \mathrm{ml})$ & $321.50^{\star \star \star}$ & $48 \cdot 3$ & 595.43 & 09.5 & $539 \cdot 15$ & $25 \cdot 60$ & $526 \cdot 98$ & $09 \cdot 57$ & $478 \cdot 43^{\star}$ & 39.90 \\
\hline \multicolumn{11}{|l|}{ Food intake } \\
\hline Food intake ( $\mathrm{g} /$ mouse per $\mathrm{d})$ & 3.45 & 0.34 & 2.96 & 0.65 & 2.91 & 0.60 & 2.78 & $0 \cdot 70$ & 2.95 & 0.41 \\
\hline
\end{tabular}

HFD, high-fat diet; FNT, formononetin; TC, total cholesterol; OCN, osteocalcin.

The mean value was significantly different from that of HFD group: ${ }^{\star} P<0.05,{ }^{\star \star} P<0.01,{ }^{\star \star \star} P<0.001,{ }^{\mathrm{b}} P<0.01$, when $10 \mathrm{mg} / \mathrm{kg}$ per $\mathrm{d}$ dose group was compared with $1 \mathrm{mg} / \mathrm{kg}$ per d dose group.

between the HFD group and the HFD supplemented with FNT groups (Table 1).

Measurement of adipose cells from H\&E-stained tissue sections (Fig. 4(A)) revealed that FNT treatment along with HFD at all doses maintained the adipose cell sizes, comparable with the chow diet group, and rescued cells from hypertrophy. This decrease in hypertrophy of cells by FNT treatment in HFD animals was further confirmed by the decrease in the levels of $P P A R \gamma$ and $C / E B P \alpha$ at both transcriptional and translational levels in adipose tissue (Fig. 4(B) and (C)). FNT treatment of mice fed HFD also effectively down-regulated the expressions of TNF $\alpha$ and leptin at all the three doses $(0 \cdot 1,1.0$ and $10.0 \mathrm{mg} / \mathrm{kg}$ per $\mathrm{d}$, respectively) (Fig. 4(B)). To investigate whether the anti-obesity effect of FNT is due to increased energy expenditure, we analysed the expressions of brown adipose tissue (BAT) markers. The main function of BAT is thermogenesis, which is mediated by up-regulation of uncoupling protein $1(U C P 1)^{(39,40)}$. We found a significant increase in the expression of $U C P 1$ in fat tissue of the HFD group treated with FNT at doses of 1 and $10 \mathrm{mg} / \mathrm{kg}$ per $\mathrm{d} \quad(P<0.05)$ (Fig. 4(D)). Moreover, other markers of thermogenesis, elongation of very long-chain fatty acid (Elovl3) and deiodinase 2 (Dio2) were also found to be significantly increased in the HFD group treated with FNT at $1(P<0.01)$ and $10 \mathrm{mg} / \mathrm{kg}$ per d doses $(P<0 \cdot 001)$, respectively, than the HFD group (Fig. 4(D)).

\section{Formononetin significantly improves biochemical parameters}

Diet-induced obesity is accompanied by major changes in physiological and biochemical parameters ${ }^{(41,42)}$. At the end of the treatment, effects on plasma lipid parameters - TC, TAG, HDL, LDL, VLDL levels - were analysed, and are presented in Table 1. These data show that FNT significantly improved hyperlipidaemia and improved cholesterol metabolism. FNTsupplemented HFD mice showed a significant decrease in plasma TC by $3 \cdot 24,30$ and $42 \%$ at $0 \cdot 1,1 \cdot 0$ and $10 \mathrm{mg} / \mathrm{kg}$ per $\mathrm{d}$ doses, respectively, compared with HFD mice. Similarly TAG levels were decreased in the FNT-treated HFD group by $42 \cdot 7$, 51.41 and $42.44 \%$ at $0.1,1.0$ and $10.0 \mathrm{mg} / \mathrm{kg}$ per d doses, respectively. Likewise, we observed changes in VLDL.

Next, we determined HDL and LDL levels in plasma. FNT treatment significantly increased HDL levels by 42.81 and $64.66 \%$ at 1.0 and $10.0 \mathrm{mg} / \mathrm{kg}$ per d doses, respectively. LDL levels were robustly increased in HFD-fed animals $(P<0 \cdot 001)$, and FNT reduced LDL levels by $26 \cdot 51,44 \cdot 8$ and $51 \cdot 49 \%$ at $0 \cdot 1$, 1 and $10 \mathrm{mg} / \mathrm{kg}$ per $\mathrm{d}$ doses, respectively, compared with the HFD diet group (Table 1).

We further examined the effect of FNT on two other biochemical markers - TNF $\alpha$ and OCN. Higher TNF $\alpha$ levels correlated with adiposity and insulin resistance. FNT treatment in HFD-treated animals decreased circulating TNF $\alpha$ levels by $54.35,38.67$ and $35.06 \%$ at $0 \cdot 1,1 \cdot 0,10 \cdot 0 \mathrm{mg} / \mathrm{kg}$ per d doses, respectively (Table 1 ). Second, circulating levels of osteocalcin, which is regarded as a specific marker for bone turnover, were increased in HFD-fed animals $(P<0.001)$, and FNT treatment significantly lowered the turnover at $10.0 \mathrm{mg} / \mathrm{kg}$ per $\mathrm{d}$ dose $(P<0.05)$ (Table 1).

\section{Formononetin restores high-fat diet-induced bone loss}

As obesity-induced bone deterioration in HFD-fed mice ${ }^{(4)}$, we next investigated whether FNT could rescue mice from HFDinduced bone loss. Fig. 5(A) shows the dosing regimen in C57BL/6 mice supplemented with HFD as well as FNT orally for 12 weeks. After 12 weeks, we analysed the effect of HFD administration on bones through micro-computed tomography $(\mu \mathrm{CT})$, as $\mu \mathrm{CT}$ is a high-resolution imaging modality that is capable of analysing bone structure with a voxel size in the order of $10 \mu \mathrm{m}^{(43)}$. Fig. 5(B) shows the 3D structure of the femoral trabecular microarchitecture obtained using $\mu \mathrm{CT}$ imaging. HFD treatment for 12 weeks resulted in deterioration of trabecular bone microarchitecture, evident by measuring $\mathrm{BV} / \mathrm{TV}$ of the distal femoral region that was decreased by $65 \%$ 
(A)
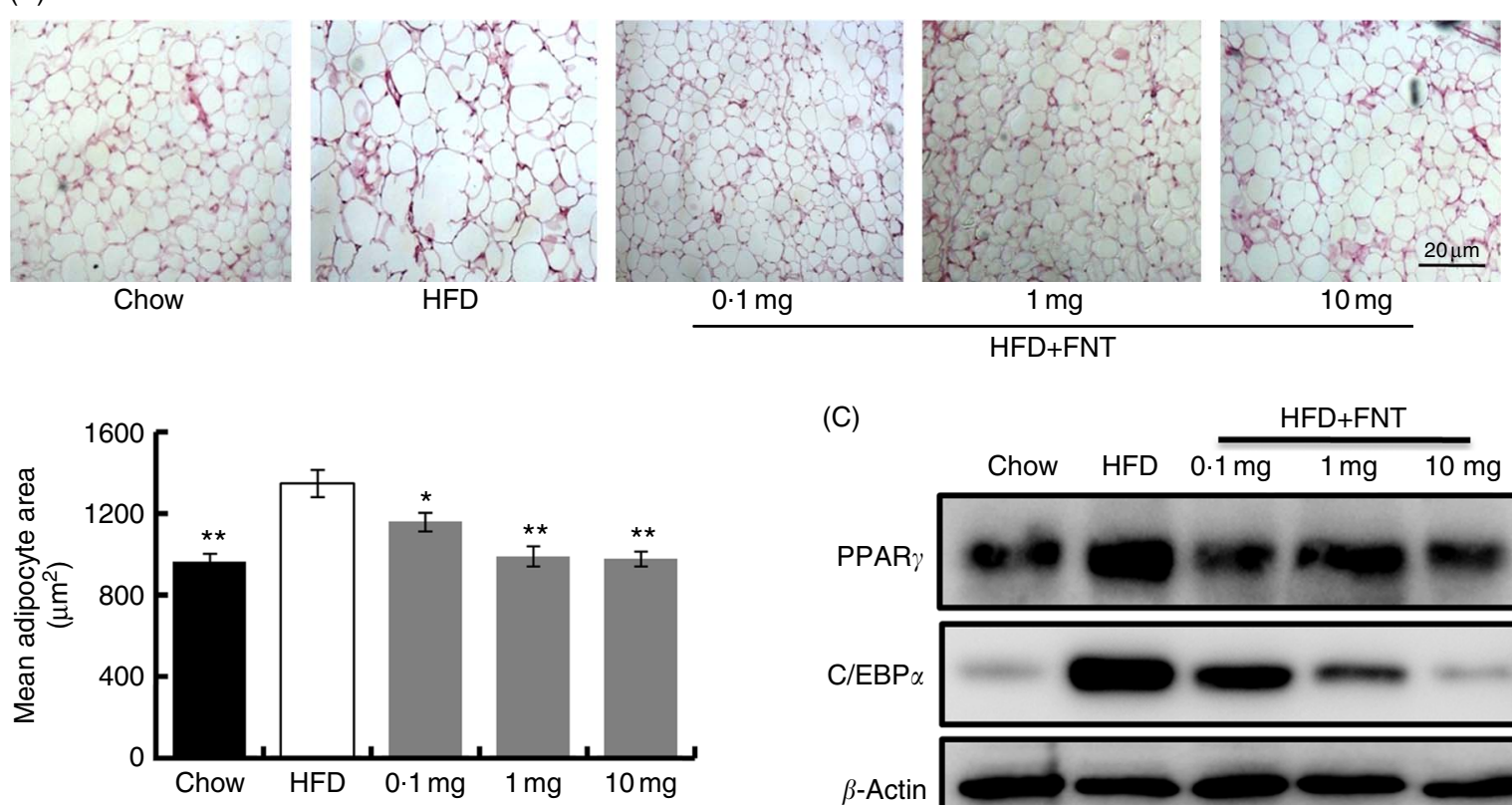

(C)
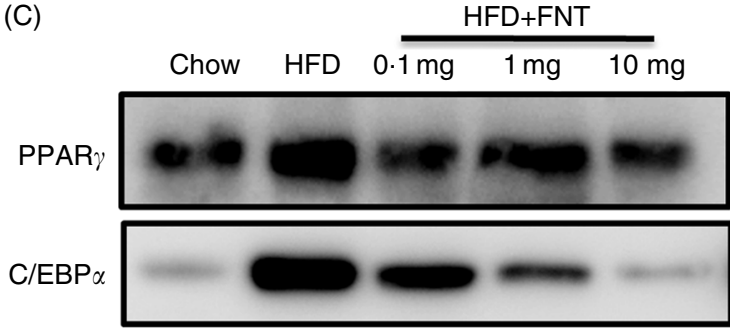

$\beta$-Actin
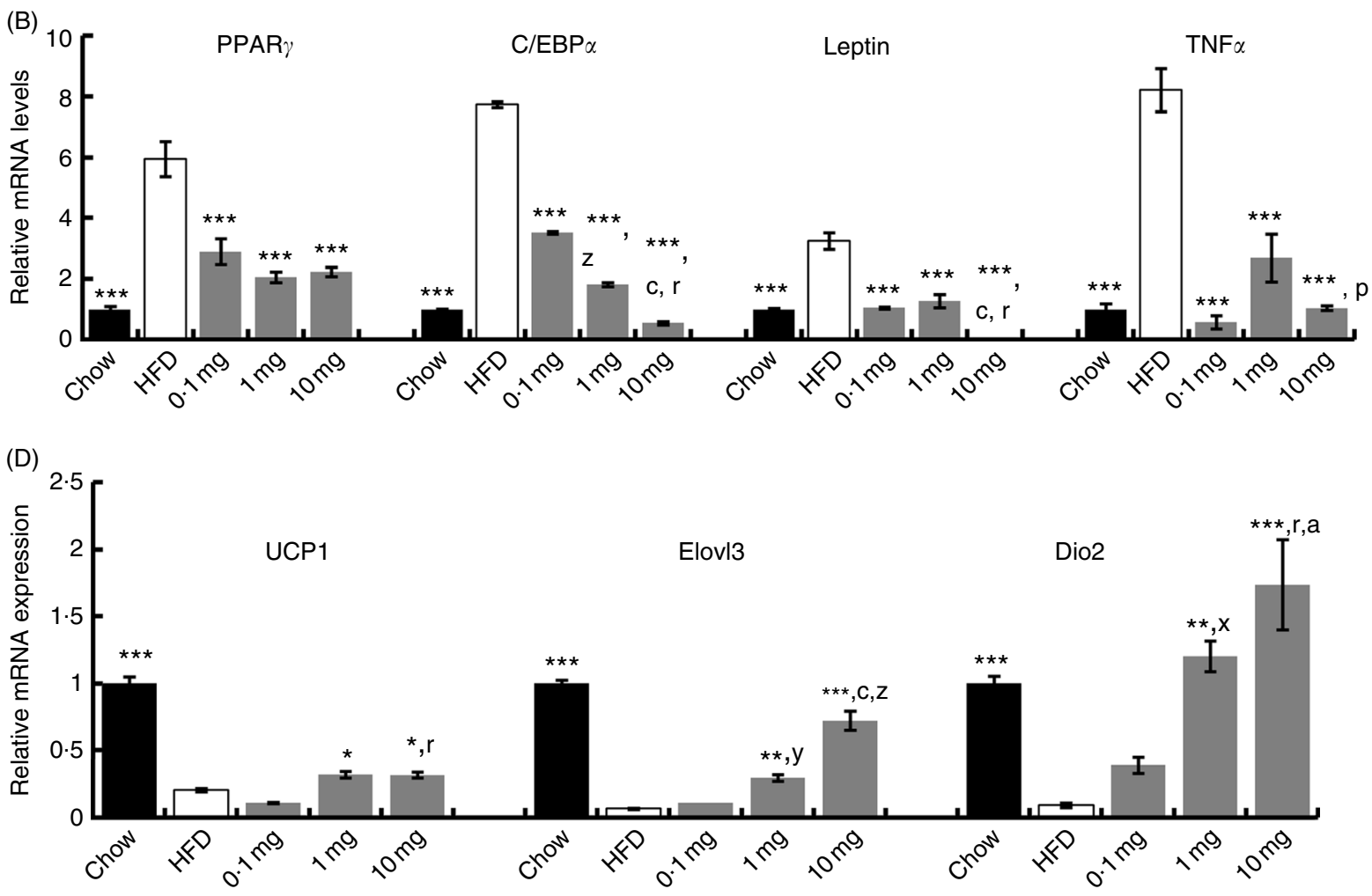

Fig. 4. Effects of formononetin (FNT) on high-fat diet (HFD)-induced obesity in C57BL/6 mice. (A) Haematoxylin-eosin staining of visceral white adipose tissue (WAT) (magnification 10x); the lower panel shows the quantitative analysis of adipocyte area using ImageJ software. (B) Real-time PCR (RT-PCR) analysis from WAT tissue of adipogenic markers and inflammatory markers - PPAR $\gamma$, CCAAT/enhancer-binding protein alpha (C/EBP $a$ ), leptin and TNF $a$. (C) Expressions of PPAR $y$ and C/EBPa in adipose tissue were assessed by Western blotting; (D) RT-PCR analysis of thermogenic genes, brown adipose tissue markers, uncoupling protein 1 (UCP1), elongation of very long-chain fatty acid (Elovl3) and deiodinase 2 (Dio2). Results were obtained from three independent experiments in triplicate and are expressed as mean values ( $n 5$ mice/group), with their standard errors. ${ }^{*} P<0.05,{ }^{\star \star} P<0.01,{ }^{\star \star \star} P<0.001$ compared with the chow group. Scale bars represent $20 \mu \mathrm{m}$ in (A). ${ }^{\mathrm{x}} P<0.05,{ }^{\mathrm{y}} P<0.01,{ }^{\mathrm{z}} P<0.001$, when $1.0 \mathrm{mg} / \mathrm{kg}$ per d dose compared with $0.1 \mathrm{mg} / \mathrm{kg}$ per d dose. ${ }^{\mathrm{P}} P<0.05,{ }^{\mathrm{r}} P<0.001$, when $10.0 \mathrm{mg} / \mathrm{kg}$ per $\mathrm{d}$ dose compared with $0.1 \mathrm{mg} / \mathrm{kg}$ per $\mathrm{d}$ dose. ${ }^{\mathrm{a}} P<0.05,{ }^{\mathrm{c}} P<0.001$, when $1.0 \mathrm{mg} / \mathrm{kg}$ per d dose compared with $10.0 \mathrm{mg} / \mathrm{kg}$ per d dose. $\square$, Chow; $\square$, HFD; $\square$, HFD+FNT. 
(A)

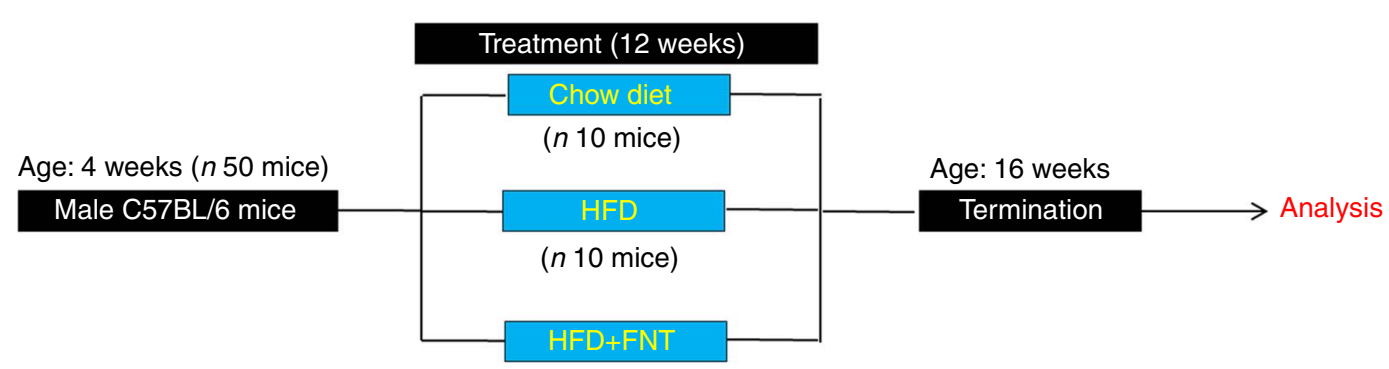

(n 10 mice $\times 3 /$ dose group)

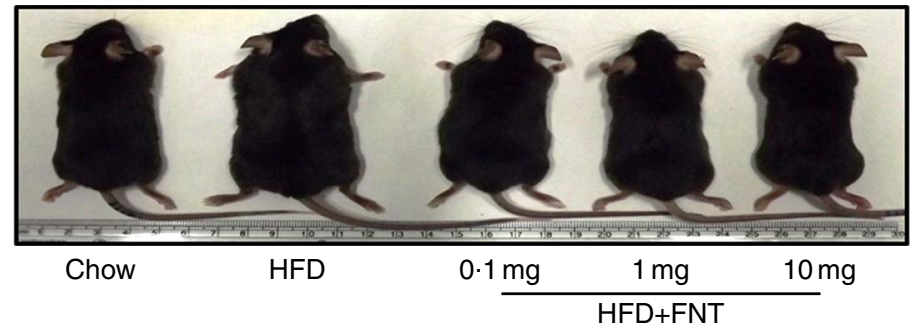

(B)

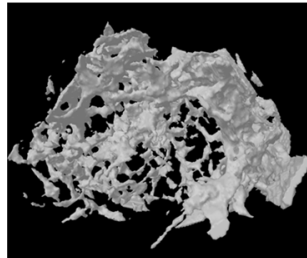

Chow

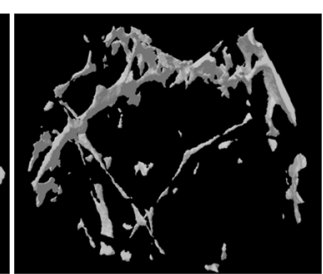

HFD

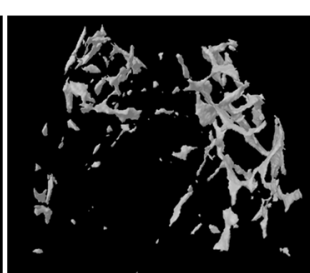

$0.1 \mathrm{mg}$

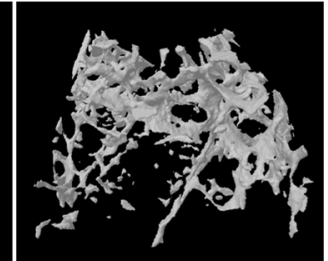

$1.0 \mathrm{mg}$

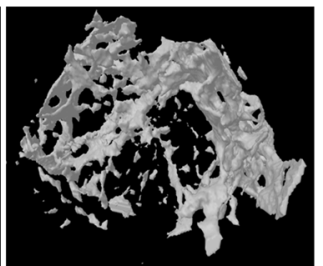

$10.0 \mathrm{mg}$

HFD+FNT

(C)

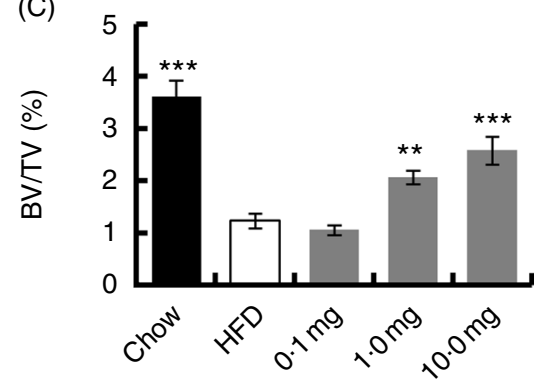

(F)

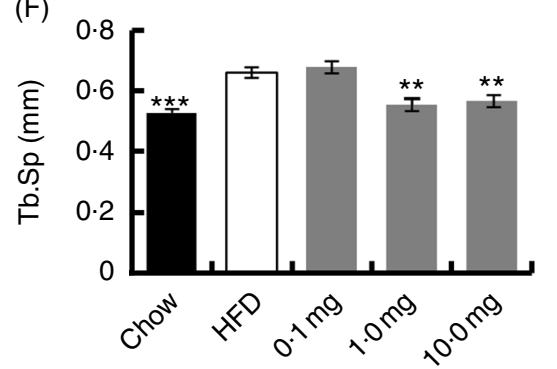

(D)

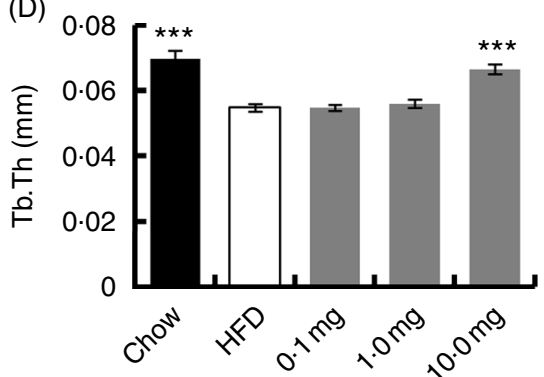

(G)

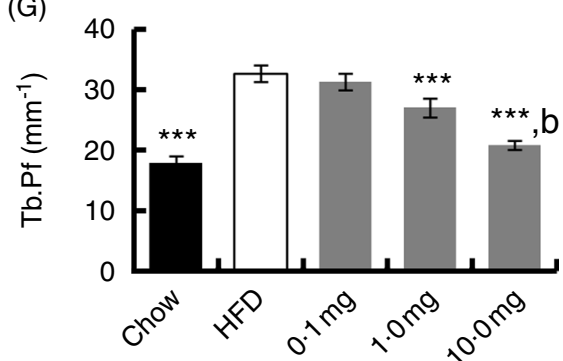

(E)

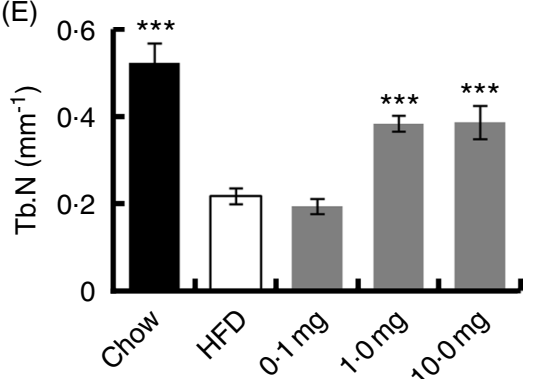

(H)

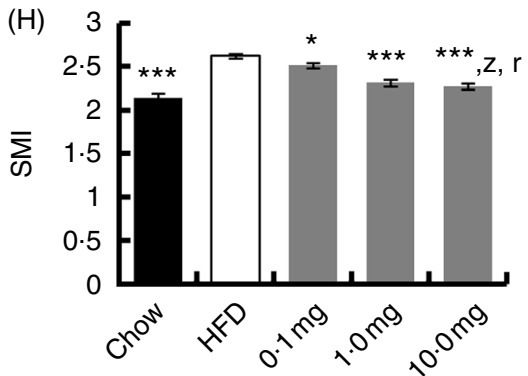

Fig. 5. Formononetin (FNT) reverses high-fat diet (HFD)-induced bone loss in obese male mice. (A) Schematic representation of the experimental study. (B) Microcomputed tomography scanning of the right femur was performed, and three-dimensional images were constructed. Bone quality was evaluated by measuring trabecular bone parameters (C) bone volume to :tissue volume (BV:TV), (D) trabecular thickness (Tb.Th), (E) trabecular number (Tb.N), (F) trabecular separation (Tb.Sp), (G) trabecular pattern factor (Tb.Pf) and (H) the structure model index (SMI). Results were obtained from three independent experiments in triplicate and are expressed as mean values ( $n 10$ mice/group), with their standard errors. ${ }^{*} P<0.05,{ }^{* *} P<0.01,{ }^{* * *} P<0.001$ compared with chow group. ${ }^{b} P<0.01$, when $10 \mathrm{mg} / \mathrm{kg}$ per d dose compared with $1 \mathrm{mg} / \mathrm{kg}$ per $\mathrm{d}$ dose. ${ }^{z} P<0.001$, when $1 \mathrm{mg} / \mathrm{kg}$ per $\mathrm{d}$ dose compared with $0.1 \mathrm{mg} / \mathrm{kg}$ per $\mathrm{d}$ dose. ${ }^{\mathrm{r}} P<0.001$, when $10.0 \mathrm{mg} / \mathrm{kg}$ per $\mathrm{d}$ dose compared with $0.1 \mathrm{mg} / \mathrm{kg}$ per d dose. $\square$, Chow; $\square$, HFD; $\square, \mathrm{HFD}+\mathrm{FNT}$. 
Table 2. Micro-architectural parameters of tibial metaphyseal region

(Mean values with their standard errors; $n 10$ mice per group)

\begin{tabular}{|c|c|c|c|c|c|c|c|c|c|c|}
\hline & & & & & \multicolumn{6}{|c|}{$\mathrm{HFD}+\mathrm{FNT}$} \\
\hline & \multicolumn{2}{|c|}{ Chow } & \multicolumn{2}{|c|}{ HFD } & \multicolumn{2}{|c|}{$\mathrm{HFD}+0.1 \mathrm{mg}$} & \multicolumn{2}{|c|}{$\mathrm{HFD}+1 \mathrm{mg}$} & \multicolumn{2}{|c|}{$\mathrm{HFD}+10 \mathrm{mg}$} \\
\hline & Mean & SEM & Mean & SEM & Mean & SEM & Mean & SEM & Mean & SEM \\
\hline BV/TV (\%) & $3.03^{\star * \star}$ & 0.32 & $1 \cdot 10$ & 0.13 & 1.38 & 0.11 & $1.6^{\star *}$ & 0.14 & $2 \cdot 12^{\star \star \star}$ & 0.18 \\
\hline Tb.Th (per mm) & $0.07^{\star \star \star}$ & 0.001 & 0.05 & 0.001 & 0.06 & 0.001 & 0.06 & 0.001 & $0.07^{\star \star \star, \mathrm{c}}$ & 0.001 \\
\hline Tb.Sp (mm) & $0.57^{\star \star \star}$ & 0.018 & 0.68 & 0.014 & 0.66 & 0.02 & 0.63 & 0.018 & $0.62^{\star *}$ & 0.011 \\
\hline Tb.N (per mm) & $0.47^{\star \star \star}$ & 0.04 & 0.19 & 0.01 & 0.24 & 0.02 & $0.27^{\star \star \star}$ & 0.02 & $0.34^{\star \star \star}$ & 0.02 \\
\hline Tb.Pf & $24 \cdot 32^{\star \star \star}$ & 1.26 & 35.85 & 1.42 & 31.68 & 0.69 & $31.07^{\star \star}$ & 0.73 & $25 \cdot 70^{\star \star \star, b}$ & 0.98 \\
\hline SMI & $2 \cdot 35^{\text {*** }}$ & 0.02 & 2.63 & 0.02 & $2 \cdot 55^{\star}$ & 0.01 & $2.49^{\star \star \star}$ & 0.02 & $2 \cdot 39^{\star \star \star}$ & 0.04 \\
\hline
\end{tabular}

HFD, high-fat diet; FNT, formononetin; BV/TV, bone volume/tissue volume; Tb.Th, trabecular thickness; Tb.Sp, trabecular separation; Tb.N, trabecular number; Tb.Pf, trabecular pattern factor; SMI, structure model index.

Significantly different from that of HFD group: ${ }^{\star} P<0.05,{ }^{\star \star} P<0.01,{ }^{\star \star *} P<0.001 ;{ }^{b} P<0.01,{ }^{\mathrm{c}} P<0.001$ when $10 \mathrm{mg} / \mathrm{kg}$ per d dose group compared with $1 \mathrm{mg} / \mathrm{kg}$ per d dose group.

Table 3. Histomorphometry and Biomechanical strength of femur

(Mean values with their standard errors; $n 10$ mice per group)

\begin{tabular}{|c|c|c|c|c|c|c|c|c|c|c|}
\hline & & & & & \multicolumn{6}{|c|}{ HFD + FNT } \\
\hline & \multicolumn{2}{|c|}{ Chow } & \multicolumn{2}{|c|}{ HFD } & \multicolumn{2}{|c|}{$\mathrm{HFD}+0.1 \mathrm{mg}$} & \multicolumn{2}{|c|}{$\mathrm{HFD}+1 \mathrm{mg}$} & \multicolumn{2}{|c|}{$\mathrm{HFD}+10 \mathrm{mg}$} \\
\hline & Mean & SEM & Mean & SEM & Mean & SEM & Mean & SEM & Mean & SEM \\
\hline \multicolumn{11}{|l|}{ Histomorphometric parameters } \\
\hline MAR $(\mu \mathrm{m} / \mathrm{d})$ & $0 \cdot 27^{\star \star}$ & 0.34 & 0.14 & 0.03 & $0 \cdot 19$ & 0.20 & $0.22^{*}$ & 0.03 & $0 \cdot 24^{*}$ & $0 \cdot 0 \cdot 16$ \\
\hline $\mathrm{pBFR} / \mathrm{BS}\left(\mu \mathrm{m}^{3} / \mu \mathrm{m}^{2}\right.$ per $\left.\mathrm{d}\right)$ & $0 \cdot 20^{\star \star}$ & 0.02 & $0 \cdot 11$ & 0.01 & $0 \cdot 14$ & 0.01 & $0 \cdot 17^{\star}$ & 0.01 & $0 \cdot 17^{*}$ & 0.01 \\
\hline \multicolumn{11}{|c|}{ Biomechanical strength related parameters } \\
\hline Power (N) & $24 \cdot 66^{\star}$ & 0.76 & $14 \cdot 16$ & $2 \cdot 22$ & 14.68 & 0.98 & $17 \cdot 78^{\star}$ & $1 \cdot 20$ & $15 \cdot 66^{*}$ & 0.59 \\
\hline Stiffness $(\mathrm{N} / \mathrm{mm})$ & $64 \cdot 18^{\star \star \star}$ & 1.63 & 37.78 & $2 \cdot 63$ & $45 \cdot 85$ & $5 \cdot 22$ & $70 \cdot 41^{\star \star}$ & 3.71 & $61 \cdot 66^{\star \star, a}$ & 5.58 \\
\hline Energy $(\mathrm{MJ})$ & $5 \cdot 51^{\star * *}$ & 0.71 & 3.25 & 0.19 & $4.58^{*}$ & 0.45 & $5 \cdot 58^{\star *}$ & 0.34 & $5 \cdot 11^{\star \star *}$ & 0.88 \\
\hline
\end{tabular}

HFD, high-fat diet; FNT, formononetin; MAR, mineral apposition rate, pBFR/BS, peripheral bone formation rate/bone surface.

Significantly different from that of HFD group: ${ }^{*} P<0.05$, ${ }^{\star *} P<0.01$, ${ }^{\star \star *} P<0.001$; ${ }^{\mathrm{a}} P<0.05$, when $10 \mathrm{mg} / \mathrm{kg}$ per d dose group was compared with $1 \mathrm{mg} / \mathrm{kg}$ per d dose group.

in the HFD group compared with the chow group (Fig. 5(C)). FNT restored HFD-induced bone loss by increasing BV/TV by 62.6 and $109 \%$ at 1 and $10 \mathrm{mg} / \mathrm{kg}$ per d doses, respectively, compared with the HFD group. Similarly, FNT increased Tb.Th at $10 \mathrm{mg} / \mathrm{kg}$ per $\mathrm{d}$ dose $(P<0.001)$ and Tb.N at 1 and $10 \mathrm{mg} / \mathrm{kg}$ per d doses, respectively, compared with the HFD group (Fig. 5(D) and (E)). When we evaluated Tb.Sp, Tb.Pf and SMI, we found a significant decrease in the following factors at both 1 and $10 \mathrm{mg} / \mathrm{kg}$ per d doses, respectively, compared with the HFD diet (Fig. 5(F-H)). Similar patterns were observed in tibia as shown in Table 2 .

We next assessed the dynamic histomorphometric parameters and mechanical strength of bone, as BFR and MAR evaluation might provide insight into the intracortical re-modelling rate. The data revealed about 48 and $45 \%$ reduction in the MAR and $\mathrm{BFR} / \mathrm{BS}$ in the HFD group, respectively. HFD mice supplemented with FNT, however, restored MAR by 35-70\% and BFR by $27-31 \%$ compared with the HFD group (Table 3 ).

The three-point bending test was used to determine the mechanical properties of the midshaft femur, as shown in Table 3. HFD treatment for 3 months resulted in significant reduction in bone biomechanical strength as evidenced by approximately $41-42 \%$ decrease in power, stiffness and energy compared with the chow group. HFD mice supplemented with
FNT preserved bone biomechanical strength by showing increased maximal load (11-20\%), stiffness (63-86\%) and energy (41-71\%) compared with the HFD group.

\section{Formononetin enhances osteogenic differentiation and decreases adipogenic differentiation of bone marrow stromal cells}

To determine the changes in the number of osteoprogenitor cells and their osteogenic potential, after 12 weeks of dietary fat treatment, bone marrow stromal cells (BMSCs) from long bones of chow, HFD and HFD supplemented with FNT groups were isolated, and ex vivo cell cultures were performed. Fig. 6(A) shows that BMSCs from the FNT-treated HFD group significantly restored ALP activity at doses of 1.0 and $10.0 \mathrm{mg} / \mathrm{kg}$ per $\mathrm{d}$, respectively $(P<0.05)$, which was significantly decreased in the HFD-treated group compared with the chow group $(P<0.01)$. The number of Alizarin-Red-stained Ca nodules, which represent the mineralising capability of the BMSCs as shown in Fig. 6(B), was decreased by approximately $50 \%(P<0.05)$ in the HFD group compared with the chow group. FNT treatment at doses of 1.0 and $10.0 \mathrm{mg} / \mathrm{kg}$ per $\mathrm{d}$ restored the mineralising capability of BMSCs. To confirm the osteoprogenitor activity of BMSCs 
(A)

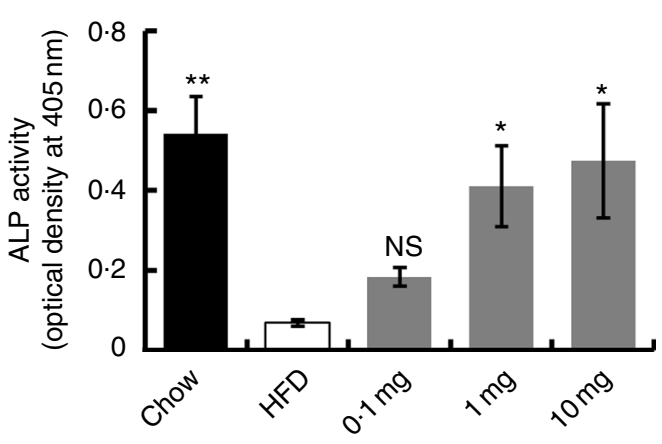

(B)
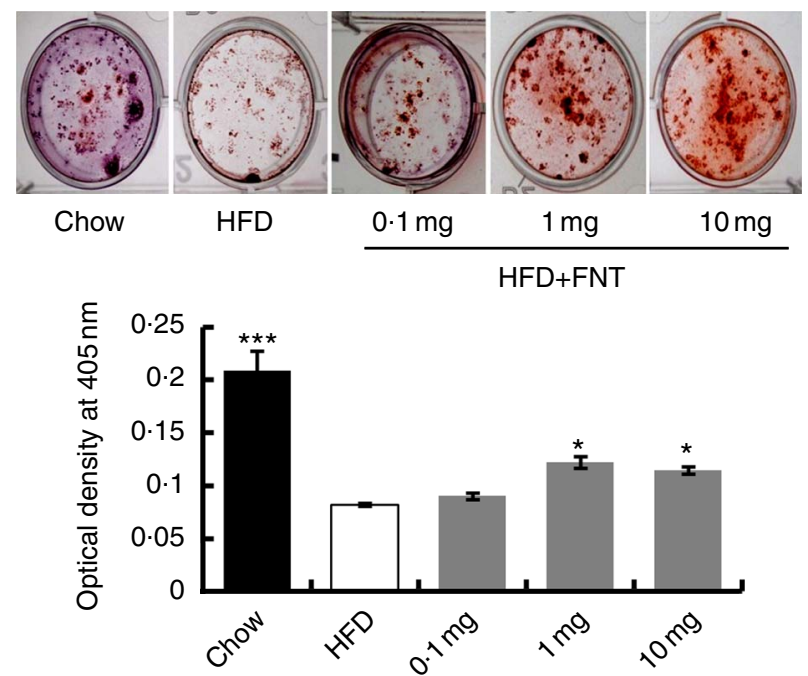

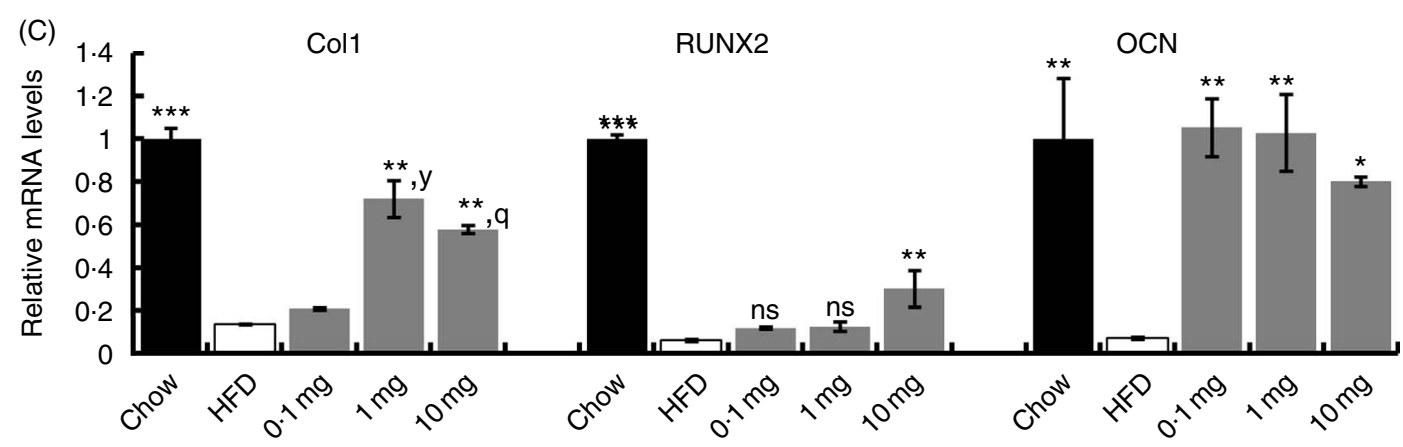

(D)

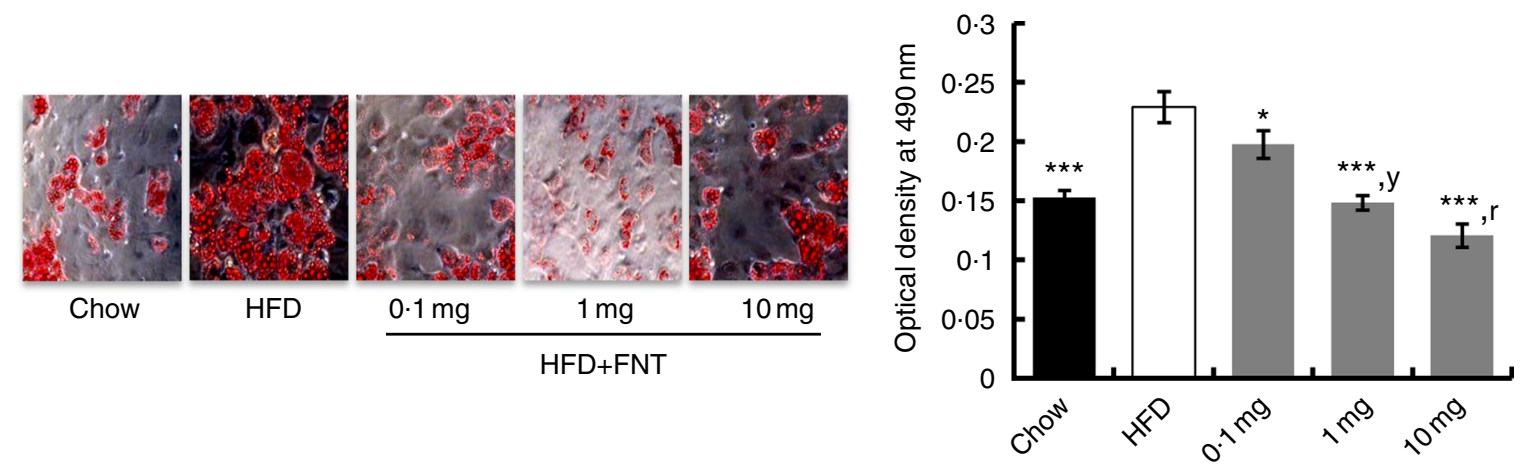

(E)

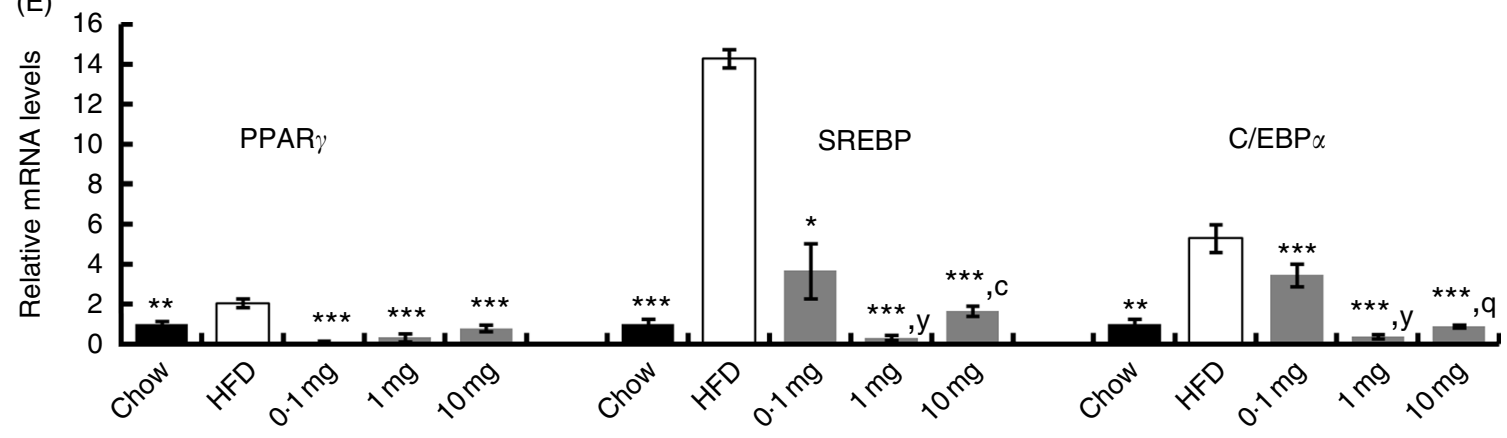

Fig. 6. (For caption see following page) 
obtained from different groups, we analysed mRNA levels of osteoblast-specific markers, collagen type-1 (Col-1), RUNX2 and $O C N$, as shown in Fig. 6(C). FNT treatment along with HFD maximally increased the expression of Col-1 at 1 and $10 \mathrm{mg} / \mathrm{kg}$ per d doses $(P<0 \cdot 01)$, RUNX2 at $10 \mathrm{mg} / \mathrm{kg}$ per d dose $(P<0 \cdot 01)$ and $O C N$ at all doses of FNT, respectively, compared with the HFD group. Fig. 6(D) shows differentiation in BMSCs towards the adipogenic lineage. Absorbance data of extracted ORO stain from the cells in the graph (right panel) show that there was about $34 \%$ increase in adipogenesis in the HFD group compared with the chow group; however, FNT treatment dose-dependently inhibited adipogenesis at $0.1 \quad(P<0.05), 1.0 \quad(P<0.01)$ and $10 \cdot 0 \mathrm{mg} / \mathrm{kg}$ per $\mathrm{d}(P<0 \cdot 001)$. This was confirmed by analysing the expressions of adipocyte-specific markers such as $P P A R \gamma$, $C / E B P \alpha$ and $S R E B P$ in differentiated BMSCs. Expressions of $P P A R \gamma, C / E B P \alpha$ and SREBP were increased by 2-, 5- and 14-fold, respectively, in BMSCs differentiated to adipocytes in the HFD group, whereas FNT treatment significantly lowered their expressions at $0 \cdot 1,1$ and $10 \mathrm{mg} / \mathrm{kg}$ per $\mathrm{d}$ doses (Fig. 6(E)).

\section{Formononetin exerts anabolic and anti-resoptive action on bone}

We next assessed the effect of 3 months of FNT treatment on the mRNA expressions of osteogenic, adipogenic and anti-resorptive genes directly in bones. Consistent with the results obtained from BMSC data, FNT treatment in HFD mice significantly restored the expressions of $O C N$ at $10 \mathrm{mg} / \mathrm{kg}$ per d dose and osteopontin $(O P N)$ at 1 and $10 \mathrm{mg} / \mathrm{kg}$ per d doses, respectively, which were decreased in the HFD group $(P<0.001)$ compared with the chow group, as shown in Fig. 7(A).

$P P A R \gamma$ activation precludes osteogenesis and enhances the activation of haematopoietic stem cells, which give rise to osteoclasts; therefore, we checked the mRNA expression of the adipocyte-specific gene $P P A R \gamma$, which was increased by $2 \cdot 0$-fold in the HFD $v$. the chow group, as shown in Fig. 7(A). FNT treatment in HFD-fed mice significantly decreased the expression levels of PPAR $\gamma$ in all dose groups (Fig. 7(A)).

These data show that expression levels of tartarate-resistant acid phosphatase (TRAP) and receptor-activated $\mathrm{NF}-\kappa \mathrm{B}$, an osteoclast marker $(R A N K)$, were increased by 2- and 9-fold, respectively, in the HFD group; however, FNT treatment in HFD-fed mice showed a marked reduction in TRAP and RANK gene expression levels at 1.0 and $10.0 \mathrm{mg} / \mathrm{kg}$ per $\mathrm{d}(P<0.001)$ doses (Fig. 7(B)). Osteoblasts and osteoclasts have been reported to be regulated by the RANK ligand (RANKL) and osteoprotegerin (OPG) during bone modelling and re-modelling, respectively. Therefore, we examined the OPG:RANKL ratio. Notably, there was a decrease in the ratio in the HFD group compared with the chow group, whereas FNT significantly increased the OPG:RANKL ratio at $10 \mathrm{mg} / \mathrm{kg}$ per $\mathrm{d}$ dose, suggesting that FNT rescues bone loss, Fig. 7(C).

\section{Discussion}

Obesity and osteoporosis are prevalent in our society and pose a major challenge to the overall health and economy ${ }^{(44)}$. There have been efforts to suppress obesity through pharmacological treatments. Many anti-obesity drugs that were initially approved by the United States Food and Drug Administration have since been withdrawn because of serious adverse effects, especially cardiovascular risks and minimal efficacy ${ }^{(45,46)}$. Therefore, there is an imperative need to identify safer and more effective treatments to inhibit obesity in the long run. Recent studies have shown Wnt-ligands as potential therapeutic agents for obesity. A variety of naturally occurring flavonoids that are activators of the Wnt $/ \beta$-catenin pathway ${ }^{(47,48)}$ have been found to possess beneficial effects on health. Overall, natural compounds having anti-obesity and anti-osteoporotic effects have drawn attention because of their relative safety.

In the present study, we have identified FNT, an isoflavone, as an AMPK and $\beta$-catenin activator. The anti-adipogenic effect of FNT shows that it inhibits the differentiation of 3T3-L1 preadipocytes with down-regulation of key transcription factors, thus restoring metabolic alterations. 3T3-L1 cells proceed through two rounds of cell division as mitotic clonal expansion and then initiate the differentiation programme ${ }^{(49)}$. When the conversion from $\mathrm{G} 1$ to $\mathrm{S}$ stage takes place, $\mathrm{C} / \mathrm{EBP} \beta$ is hypophosphorylated and sequentially gets activated by glycogen synthase kinase- $3 \beta$ and MAPK, and finally both $\mathrm{C} / \mathrm{EBP} \beta$ and $\mathrm{C} / \mathrm{EBP} \delta$ directly induce the expressions of PPAR $\gamma$ and $\mathrm{C} / \mathrm{EBP} \alpha$. FNT stopped the transition of cells from G1 to $S$ stage with down-regulation of MAPK levels (online Supplementary Fig. S1) and decreased the expressions of PPAR $\gamma$ and $\mathrm{C} / \mathrm{EBP} \alpha$.

Further, to obtain an insight into the anti-adipogenic activity, we found that FNT inhibited adipogenesis through ROS-induced AMPK activation. It has been studied that increased oxidative stress is responsible for the inhibition of adipogenesis during ageing ${ }^{(38)}$. Reports have already shown that ROS may activate the AMPK pathway. Some of the major isoflavones such as genistein, phytochemicals such as epigallocatechin gallate or capsaicin as well as 5-aminoimidazole4-carboxamide ribonucleotide (AICAR), an analogue of AMP (AMPK activator), have been shown to suppress adipogenesis through AMPK activation and ROS generation ${ }^{(21,50)}$. Likewise, we observed that FNT too activated the AMPK pathway via ROS generation and inhibited the adipogenic differentiation of 3T3-L1 cells. AMPK has a key role in the development of

Fig. 6. (For figure see previous page) Formononetin (FNT) reverses high-fat diet (HFD)-induced commitment of bone marrow stromal cells (BMSCs). BMSCs were isolated from chow, HFD and FNT-supplemented with HFD groups and differentiated towards adipogenic and osteogenic lineage. (A) Alkaline phosphatase (ALP) activity was measured on the basis of absorbance at $405 \mathrm{~nm}$ ( $n 3$; left panel). (B) Alizarin Red S staining (right upper panel) and quantification was performed by measuring absorbance at $405 \mathrm{~nm}$ ( $n$ 3; right lower panel). (C) mRNA expression of osteogenic markers collagen type-1 (Col1), runt-related transcription factor 2 (RUNX2) and osteocalcin (OCN) in BMSC. (D) Oil Red O staining (left panel). Quantification of Oil red O staining was performed by measuring absorbance at $590 \mathrm{~nm}$ ( $n$ 3; right panel) and (E) mRNA expressions of adipogenic markers PPARy, CCAAT/enhancer-binding protein alpha (C/EBPa) and sterol regulatory element-binding protein (SREBP) in BMSC. Results were obtained from three independent experiments in triplicate and are expressed as means ( $n 5$ mice/group), with their standard errors. ${ }^{\star} P<0.05$, ${ }^{\star \star} P<0.01$, ${ }^{\star \star \star} P<0.001$ compared with chow group. ${ }^{\mathrm{y}} P<0.01$, when $1.0 \mathrm{mg} / \mathrm{kg}$ per d dose compared with $0.1 \mathrm{mg} / \mathrm{kg}$ per d dose. ${ }^{\mathrm{q}} P<0.01,{ }^{\mathrm{r}} P<0.001$, when $10.0 \mathrm{mg} / \mathrm{kg}$ per $\mathrm{d}$ dose compared with $0.1 \mathrm{mg} / \mathrm{kg}$ per d dose. ${ }^{\mathrm{C}} P<0.001$, when $1.0 \mathrm{mg} / \mathrm{kg}$ per d dose compared with $10.0 \mathrm{mg} / \mathrm{kg}$ per d dose. ${ }^{*} P<0.05,{ }^{\star *} P<0.01,{ }^{\star \star *} P<0.001$. $\square$, Chow; $\square$, HFD; $\square, \mathrm{HFD}+\mathrm{FNT}$. 

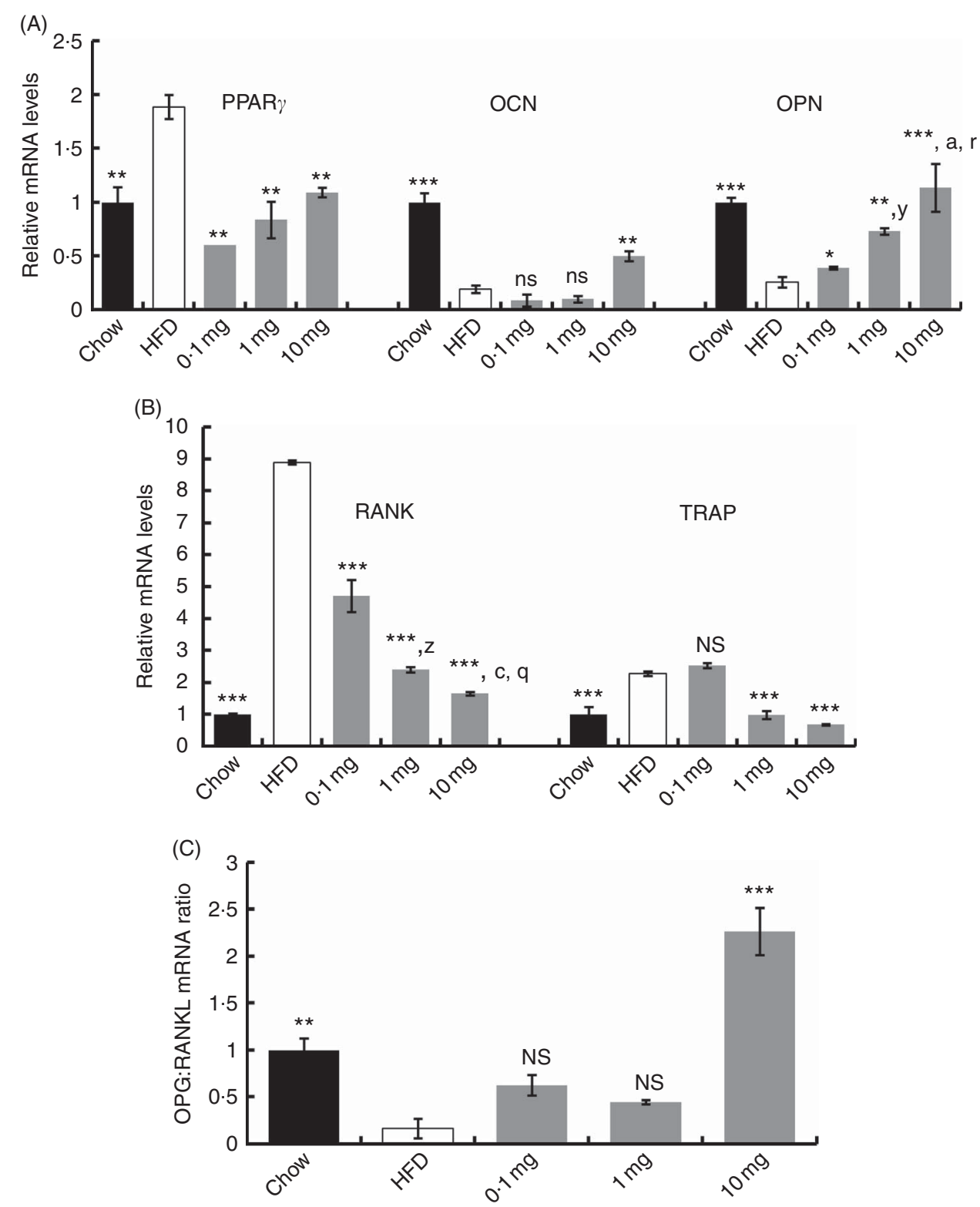

Fig. 7. Effect of formononetin (FNT) on the expressions of osteogenic, adipogenic and resorptive genes in obese male mouse bone. Real-time PCR (RT-PCR) was performed on bone samples from the mice fed a normal diet and high-fat diet (HFD) with or without FNT. mRNA expressions of (A) PPARy, osteocalcin (OCN), osteopontin (OPN) and resorptive genes, (B) receptor-activated NF-KB (RANK), tartarate-resistant acid phosphatase (TRAP) and (C) osteoprotegerin:RANK ligand (OPG:RANKL) ratio. The expressions of genes were normalised to that of glyceraldehyde 3-phosphate dehydrogenase (GAPDH). Results were obtained from three independent experiments in triplicate and are expressed as means ( $n 5$ mice/group), with their standard errors. ${ }^{*} P<0.05,{ }^{* *} P<0.01,{ }^{* * *} P<0.001$ compared with chow group. ${ }^{y} P<0.01,{ }^{z} P<0.001$, when $1.0 \mathrm{mg} / \mathrm{kg}$ per $\mathrm{d}$ dose compared with $0.1 \mathrm{mg} / \mathrm{kg}$ per d dose. ${ }^{\mathrm{q}} P<0.01,{ }^{\mathrm{r}} P<0.001$, when $10.0 \mathrm{mg} / \mathrm{kg}$ per d dose compared with $0.1 \mathrm{mg} / \mathrm{kg}$ per d dose. ${ }^{\mathrm{a}} P<0.05$, ${ }^{\mathrm{c}} P<0.001$, when $1.0 \mathrm{mg} / \mathrm{kg}$ per $\mathrm{d}$ dose compared with $10.0 \mathrm{mg} / \mathrm{kg}$ per $\mathrm{d}$ dose. $\mathrm{c}$, Chow; $\square, \mathrm{HFD} ; \square, \mathrm{HFD}+\mathrm{FNT}$.

obesity. The metabolic syndrome, which is a cluster of related metabolic abnormalities including insulin resistance, abdominal obesity, hypertension and altered plasma lipids, especially hypertriacylglycerolaemia and low HDL-cholesterol, is potentially reversed by AMPK activation ${ }^{(51)}$. Exercise is a best prevention tool for these altered physiological conditions, and it has been speculated that during exercise increase in AMPK phosphorylation is one of the major conviction ${ }^{(52)}$. In our study, we found FNT to be a potential activator of AMPK.

Further studies have documented that AMPK regulates cell differentiation via altering $\beta$-catenin expression $^{(8)}$.
Adipogenesis progresses through $\beta$-catenin-dependent or $\beta$-catenin-independent pathways, and some studies have shown $\beta$-catenin as an independent inhibitor of adipogenesis $^{(8,9,19)}$; therefore, we investigated the expression of $\beta$-catenin. FNT treatment stabilises the expression of $\beta$-catenin along with activation of AMPK. Next, we examined whether this $\beta$-catenin stabilisation was GSK- $3 \beta$ dependent, as Axin and adenomatous polyposis coli (APC) act as scaffolding proteins that facilitate GSK-3 $\beta$ to phosphorylate $\beta$-catenin ${ }^{(19)}$. FNT increased the phosphorylation of GSK-3 $\beta$ (Ser-9), which rescued $\beta$-catenin degradation and increased its nuclear 
localisation. In addition to this, we also investigated whether FNT affects the Wnt target genes, as studies have shown a crossrelationship between AMPK and $\mathrm{Wnt} / \beta$-catenin pathway ${ }^{(\mathcal{9}, 53)}$. Wnt-10b is a potent inhibitor of adipogenesis that must be suppressed for pre-adipocyte differentiation in vitro. We found that FNT treatment increased the transcriptional levels of Wnt-10b and nuclear accumulation of $\beta$-catenin. However, a deeper investigation is required to confirm the Wnt-pathway activation, as Ser-9 of GSK- $3 \beta$ is not regulated cells that are activated by Wnt or dishevelled ${ }^{(54)}$. We majorly favour the involvement of AMPK and $\beta$-catenin in the anti-adipogenic activity of FNT. It is also possible that either FNT suppresses adipogenesis through independent actions of AMPK and $\beta$-catenin or through their cross-talk

Our observations that FNT regulates AMPK and mediates anti-adipogenic effects via the $\beta$-catenin pathway have important physiological implications. AMPK has a central role in the regulation of energy metabolism and is regulated by numerous factors. In addition, AMPK is modulated by adipokines such as adiponectin and resistin and cytokines such as monocyte chemoattractant protein-1. We found that FNT modulated their expressions, as observed using the adipokine array (online Supplementary Fig. S3). This cross-talk of AMPK with the $\beta$-catenin pathway may exert long-term effects on tissue development and physiological functions, as both these signalling pathways are widely expressed in various tissues and conserved in the animal kingdom.

To further validate the effectiveness of FNT against obesity and the metabolic syndrome, we used an HFD-induced obese mouse model. HFD induces obesity in both humans and mice. FNT decreased total body weight of the $\mathrm{C} 57 \mathrm{BL} / 6$ mice group on HFD. However, FNT did not decrease food intake; therefore, we sought to determine whether the anti-obesity effect of FNT is due to increased energy expenditure. As expected, we found increased expressions of thermogenic regulators such as UCP1, Elovl3 and Dio2 in the FNT-supplemented group. Mammals have two types of adipose tissue - one is white adipose tissue that specialises in lipid storage and undergoes pathological expansion during obesity, and the other is thermogenic BAT. BAT is a key thermogenic tissue in rodents and other small mammals, including newborn humans that defend core body temperature in cold weather ${ }^{(40)}$. BAT evolved in mammals to dissipate large amounts of chemical energy as heat. Classic experiments in rodents have shown that BAT is activated and proliferates in response to over-feeding ${ }^{(39)}$. This so-called 'diet-induced adaptive thermogenesis' is an apparent compensatory mechanism to limit excess weight gain and obesity. Brown fat cells possess large numbers of mitochondria that contain a unique protein called $\mathrm{UCP} 1^{(55)}$. With the help of UCP1, the energy in the mitochondrial electrochemical gradient is released in the form of heat ${ }^{(40,55)}$. A therapy for weight loss must, therefore, involve a decrease in food intake and/or an increase in energy expenditure. In this case, FNT increased energy expenditure.

FNT effectively improved deregulated lipid levels in blood, aggravated by obesity and enlargement of adipose tissue by hypertrophy or hyperplasia. Obesity is also associated with low-grade chronic inflammation within fat tissue. TNF $\alpha$, a pro-inflammatory marker expressed in and secreted by adipose tissue, is effectively suppressed by FNT in plasma and adipose tissue. Targeting TNF $\alpha$ and/or its receptors has been suggested as a promising treatment for insulin resistance and type 2 diabetes. We observed that FNT prevented fatty liver condition that abolished the concern of lipotoxicity (online Supplementary Fig. S2B) and suggests a possibility to develop an anti-obesity therapy without diet adjustments. Oestrogen depletion is one of the main causes of bone loss and osteoporosis; therefore, osteoporosis has been considered to be a female disease. However, our study indicates that abdominal fat is also an osteoporosis alarm for $m e n^{(4)}$. Our present study focused on male mice, as males are more prone to obesity-induced bone loss. The bone loss induced by HFD was reversed by treatment with FNT as shown by $\mu \mathrm{CT}$ analysis. We found that FNT can be administered orally as a food supplement. Our data also show that FNT can inhibit the differentiation of pre-adipocytes. Thus, a small molecule that activates the AMPK/ $\beta$-catenin pathway in this manner may represent a potential new class of anti-obesity supplements that can be easily administered.

\section{Conclusion}

In conclusion, our study demonstrates that the isoflavone FNT (1) has an anti-obesity effect in HFD-induced obese mice, (2) prevents obesity-induced bone loss, (3) activates the AMPK/ $\beta$-catenin pathway and (4) increases energy expenditure via up-regulation of UCP1 under HFD conditions. These findings suggest that FNT has the potential to be a therapeutic for the treatment of obesity. We have validated the effect of FNT on an HFD-induced obesity mouse model as a representative model of human obesity.

\section{Acknowledgements}

The authors gratefully acknowledge generous funding from the Council of Scientific and Industrial Research (CSIR-BSC0201, ASTHI), Indian Council of Medical Research (ICMR), Department of Biotechnology (DBT), Government of India. The funders had no role in study design, data collection, data analysis or manuscript preparation.

Study conception and design: J. G., V. K., P. K., R. M., K. D., P. D., G. K. N., R. T; acquisition of data: J. G., P. K., V. K., D. C., G. K. N; analysis and interpretation of data: P. K., V. K., J. G., R. T; drafting of manuscript: J. G., R. T., D. S.; critical revision: P. D., R. M., D. S., P. K., V. K., D. C., J. G., R. T.

All authors declare no conflicts of interest.

\section{Supplementary material}

To view the supplementary material for this article, please visit https://doi.org/10.1017/S0007114517000149

\section{References}

1. Kawai M, Devlin MJ \& Rosen CJ (2009) Fat targets for skeletal health. Nat Rev Rheumatol 5, 365-372.

2. Gerbaix M, Metz L, Mac-Way F, et al. (2012) Impact of an obesogenic diet program on bone densitometry, micro architecture and metabolism in male rat. Lipids Health Dis 11, 91. 
3. Lu XM, Zhao H \& Wang EH (2013) A high-fat diet induces obesity and impairs bone acquisition in young male mice. $\mathrm{Mol}$ Med Rep 7, 1203-1208.

4. Gautam J, Choudhary D, Khedgikar V, et al. (2014) Microarchitectural changes in cancellous bone differ in female and male C57BL/6 mice with high-fat diet-induced low bone mineral density. Br J Nutr 111, 1811-1821.

5. Rosen CJ \& Bouxsein ML (2006) Mechanisms of disease: is osteoporosis the obesity of bone? Nat Clin Pract Rheumatol $\mathbf{2}$, $35-43$.

6. Xiao Y, Cui J, Li YX, et al. (2010) Expression of genes associated with bone resorption is increased and bone formation is decreased in mice fed a high-fat diet. Lipids $\mathbf{4 5}$, 345-355.

7. Viollet B, Horman S, Leclerc J, et al. (2010) AMPK inhibition in health and disease. Crit Rev Biochem Mol Biol 45 , 276-295.

8. Zhao JX, Yue WF, Zhu MJ, et al. (2011) AMP-activated protein kinase regulates beta-catenin transcription via histone deacetylase 5. J Biol Chem 286, 16426-16434.

9. Zhao J, Yue W, Zhu MJ, et al. (2010) AMP-activated protein kinase (AMPK) cross-talks with canonical Wnt signaling via phosphorylation of beta-catenin at Ser 552. Biochem Biophys Res Commun 395, 146-151.

10. Bennett CN, Longo KA, Wright Ws, et al. (2005) Regulation of osteoblastogenesis and bone mass by Wnt10b. Proc Natl Acad Sci U S A 102, 3324-3329.

11. Bennett CN, Ross SE, Longo KA, et al. (2002) Regulation of Wnt signaling during adipogenesis. J Biol Chem 277, 30998-31004.

12. Gaur T, Lengner CJ, Hovhannisyan H, et al. (2005) Canonical WNT signaling promotes osteogenesis by directly stimulating Runx2 gene expression. J Biol Chem 280, 33132-33140.

13. Longo KA, Wright WS, Kang S, et al. (2004) Wnt10b inhibits development of white and brown adipose tissues. J Biol Chem 279, 35503-35509.

14. Ross SE, Hemati N, Longo KA, et al. (2000) Inhibition of adipogenesis by Wnt signaling. Science 289, 950-953.

15. Liu J, Wang H, Zuo Y, et al. (2006) Functional interaction between peroxisome proliferator-activated receptor gamma and beta-catenin. Mol Cell Biol 26, 5827-5837.

16. Li FQ, Singh AM, Mofunanya A, et al. (2007) Chibby promotes adipocyte differentiation through inhibition of beta-catenin signaling. Mol Cell Biol 27, 4347-4354.

17. Jin T, George Fantus I \& Sun J (2008) Wnt and beyond Wnt: multiple mechanisms control the transcriptional property of beta-catenin. Cell Signal 20, 1697-1704.

18. Villanueva CJ, Waki H, Godio C, et al. (2011) TLE3 is a dualfunction transcriptional coregulator of adipogenesis. Cell Metab 13, 413-427.

19. Cawthorn WP, Bree AJ, Yao Y, et al. (2012) Wnt6, Wnt10a and Wnt10b inhibit adipogenesis and stimulate osteoblastogenesis through a beta-catenin-dependent mechanism. Bone 50, 477-489.

20. Orgaard A \& Jensen L (2008) The effects of soy isoflavones on obesity. Exp Biol Med (Maywood) 233, 1066-1080.

21. Hwang JT, Park IJ, Shin JI, et al. (2005) Genistein, EGCG, and capsaicin inhibit adipocyte differentiation process via activating AMP-activated protein kinase. Biochem Biophys Res Commun 338, 694-699.

22. Gautam J, Khedgikar V, Choudhary D, et al. (2016) An isoflavone cladrin prevents high-fat diet-induced bone loss and inhibits the expression of adipogenic gene regulators in 3T3-L1 adipocyte. J Pharm Pharmacol 68 , 1051-1063.
23. Cooke PS \& Naaz A (2004) Role of estrogens in adipocyte development and function. Exp Biol Med (Maywood) 229, $1127-1135$

24. Maurya R, Yadav DK, Singh G, et al. (2009) Osteogenic activity of constituents from Butea monosperma. Bioorg Med Chem Lett 19, 610-613.

25. Wu JH, Li Q, Wu MY, et al. (2010) Formononetin, an isoflavone, relaxes rat isolated aorta through endotheliumdependent and endothelium-independent pathways. $J$ Nutr Biochem 21, 613-620

26. Chen J, Zhao X, Ye Y, et al. (2013) Estrogen receptor betamediated proliferative inhibition and apoptosis in human breast cancer by calycosin and formononetin. Cell Physiol Biochem 32, 1790-1797.

27. Huang WJ, Bi LY, Li ZZ, et al. (2013) Formononetin induces the mitochondrial apoptosis pathway in prostate cancer cells via downregulation of the IGF-1/IGF-1R signaling pathway. Pharm Biol 52, 466-470.

28. Jin YM, Xu TM, Zhao YH, et al. (2014) In vitro and in vivo anticancer activity of formononetin on human cervical cancer cell line HeLa. Tumour Biol 35, 2279-2284.

29. Gautam AK, Bhargavan B, Tyagi AM, et al. (2011) Differential effects of formononetin and cladrin on osteoblast function, peak bone mass achievement and bioavailability in rats. J Nutr Biochem 22, 318-327.

30. Tyagi AM, Srivastava K, Singh AK, et al. (2012) Formononetin reverses established osteopenia in adult ovariectomized rats. Menopause 19, 856-863

31. Gao Y, Zhou Y, Xu A, et al. (2008) Effects of an AMPactivated protein kinase inhibitor, compound $\mathrm{C}$, on adipogenic differentiation of 3T3-L1 cells. Biol Pharm Bull 31, 1716-1722.

32. Lee JA, Song HY, Ju SM, et al. (2009) Differential regulation of inducible nitric oxide synthase and cyclooxygenase-2 expression by superoxide dismutase in lipopolysaccharide stimulated RAW 264.7 cells. Exp Mol Med 41, 629-637.

33. Khedgikar V, Gautam J, Kushwaha P, et al. (2012) A standardized phytopreparation from an Indian medicinal plant (Dalbergia sissoo) has antiresorptive and bone-forming effects on a postmenopausal osteoporosis model of rat. Menopause 19. 1336-1346.

34. Khedgikar V, Kushwaha P, Gautam J, et al. (2013) Withaferin A: a proteasomal inhibitor promotes healing after injury and exerts anabolic effect on osteoporotic bone. Cell Death Dis $\mathbf{4}$, e778.

35. Sashidhara KV, Kumar M, Khedgikar V, et al. (2013) Discovery of coumarin-dihydropyridine hybrids as bone anabolic agents. J Med Chem 56, 109-122.

36. Gautam J, Kumar P, Kushwaha P, et al. (2015) Neoflavonoid dalbergiphenol from heartwood of Dalbergia sissoo acts as bone savior in an estrogen withdrawal model for osteoporosis. Menopause 22, 1246-1255.

37. Parlee SD, Lentz SI, Mori H, et al. (2014) Quantifying size and number of adipocytes in adipose tissue. Methods Enzymol 537, 93-122.

38. Findeisen HM, Pearson KJ, Gizard F, et al. (2011) Oxidative stress accumulates in adipose tissue during aging and inhibits adipogenesis. PLOS ONE 6, e18532.

39. Rothwell NJ \& Stock MJ (1983) Diet-induced thermogenesis. Adv Nutr Res 5, 201-220.

40. Seale P \& Lazar MA (2009) Brown fat in humans: turning up the heat on obesity. Diabetes 58, 1482-1484.

41. Bhathena SJ \& Velasquez MT (2002) Beneficial role of dietary phytoestrogens in obesity and diabetes. Am J Clin Nutr $\mathbf{7 6}$, $1191-1201$ 
42. Xiao Y, Cui J, Li YX, et al. (2011) Dyslipidemic high-fat diet affects adversely bone metabolism in mice associated with impaired antioxidant capacity. Nutrition 27, 214-220.

43. Campbell GM \& Sophocleous A (2014) Quantitative analysis of bone and soft tissue by micro-computed tomography: applications to ex vivo and in vivo studies. Bonekey Rep 3, 564.

44. Lecka-Czernik B \& Stechschulte LA (2014) Bone and fat: a relationship of different shades. Arch Biochem Biophys 561, 124-129.

45. Rodgers RJ, Tschop MH \& Wilding JP (2012) Anti-obesity drugs: past, present and future. Dis Model Mech 5, 621-626.

46. Heal DJ, Gosden J \& Smith SL (2009) Regulatory challenges for new drugs to treat obesity and comorbid metabolic disorders. Br J Clin Pharmacol 68, 861-874.

47. Kushwaha P, Khedgikar V, Gautam J, et al. (2014) A novel therapeutic approach with Caviunin-based isoflavonoid that en routes bone marrow cells to bone formation via BMP2/ Wnt-beta-catenin signaling. Cell Death Differ 5, e1422.

48. Liang HD, Yu F, Lv P, et al. (2014) Role of sost in Wnt signal pathway in osteoporosis rats and regulating effect of soybean isoflavones on Wnt signal pathway. Mol Biol Rep 41, 4447-4454.
49. Tang QQ, Otto TC \& Lane MD (2003) Mitotic clonal expansion: a synchronous process required for adipogenesis. Proc Natl Acad Sci U S A 100, 44-49.

50. Gautam J, Kushwaha P, Swarnkar G, et al. (2012) EGb 761 promotes osteoblastogenesis, lowers bone marrow adipogenesis and atherosclerotic plaque formation. Phytomedicine 19. 1134-1142.

51. Hardie DG (2008) AMPK: a key regulator of energy balance in the single cell and the whole organism. Int J Obes (Lond) $\mathbf{3 2}$, Suppl. 4, S7-S12.

52. Richter EA \& Ruderman NB (2009) AMPK and the biochemistry of exercise: implications for human health and disease. Biochem J 418, 261-275.

53. Lee H, Kang R, Bae S, et al. (2011) AICAR, an activator of AMPK, inhibits adipogenesis via the WNT/beta-catenin pathway in 3T3-L1 adipocytes. Int J Mol Med 28, 65-71.

54. Ding VW, Chen RH \& McCormick F (2000) Differential regulation of glycogen synthase kinase 3 beta by insulin and Wnt signaling. J Biol Chem 275, 32475-32481.

55. Cannon B \& Nedergaard J (2004) Brown adipose tissue: function and physiological significance. Physiol Rev 84, 277-359. 